\title{
TRAC98: DETECTION OF COHERENT STRUCTURES IN A CONVECTIVE BOUNDARY LAYER USING AIRBORNE MEASUREMENTS
}

\author{
SANDRINE BERNARD-TROTTOLO, B. CAMPISTRON, A. DRUILHET, F. LOHOU \\ and F. SAÏD ${ }^{\star}$ \\ Laboratoire d'Aérologie, UMR CNRS/UPS 5560, Observatoire Midi Pyrénées, Université Paul \\ Sabatier, France
}

\begin{abstract}
The TRAC98 experimental campaign (Turbulence Radar Aircraft Cells) devoted to coherent structures analysis took place over the Beauce plain (France) during summer 1998. It allowed us to collect a large dataset of airborne measurements in addition to various ground measurements. This study aims at diagnosing the occurrence of coherent structures within the atmospheric boundary layer (ABL) through airborne measurements. The statistical analysis performed as a first step from turbulent parameters underlined the homogeneity of the ABL over the Beauce plain. However mixedlayer scaling failed at the top of the ABL, even when taking into account the entrainment rate. Coherent structures were detected through the analysis of ABL isotropy, using the opportunity of sampling with two perpendicular crossing planes, one of them being aligned with the wind. This approach allowed us to determine an organization scheme of the ABL for three of the five flights (ARAT30, MIV30 and MIV27). For the ARAT30 flight, the analysis was pursued by focusing on measurements of fluctuations in the inner flight legs. In this way, the low-level cloud cover has been investigated from the downward visible radiation (VISD). The results indicated an anisotropy of the horizontal cloud size. Secondly, the variations of some parameters were analysed through lagged correlation functions. This allowed us to infer relationships between the vertical velocity, VISD, mixing ratio and lifting condensation level. Length scales have also been extracted, and confirmed the ABL organization during the ARAT30 flight. Finally, the anisotropy observed in various flights has been investigated with respect to the underestimation of the latent heat fluxes revealed by the imbalance of the surface energy budget.
\end{abstract}

Keywords: Anisotropy, Atmospheric boundary layer, Atmospheric turbulence, Coherent structures, Convective boundary layers, TRAC98 experiment.

\section{Introduction}

Analysis of coherent structures in the convective atmospheric boundary layer (ABL) has been going on for some ten years. There has been a revival of interest due to the development of new means to observe and study them, both from experimental and numerical points of view. The first studies that addressed the possible organization of the atmospheric boundary layer had to face a lack of direct means

^ Corresponding address: CNRS-Laboratoire d'Aérologie, CRA de Campistrous, 8 rte de Lannemezan, 65300 Campistrous. E-mail: saif@aero.obs-mip.fr 
to observe and classify the organization. Previously, roll occurrence was associated with the existence of cloud streets or linear bands of steam, fog or haze (Kuettner, 1971; LeMone, 1973; Brümmer, 1985, 1999). Agee (1984) for instance described the satellite meteorology program devoted to studies of mesoscale cellular convection. Now, it is known that the ABL organization can also occur in clear air (Weckwerth, 1996). For that reason, the recently developed remote sensing tools that work in clear air are of great interest. The RONSARD Doppler radar is one of them (Eymard and Weill, 1982; Scialom and Lemaitre, 1990). The horizontal reflectivity cross sections obtained with this tool allow the analysis of coherent structure characteristics (Lohou et al., 1998b). Heterodyne Doppler lidars are also able to provide information about ABL organization in clear air (Drobinski et al., 1998). Etling and Brown (1993) reviewed the analysis of roll vortices observed with these new means. Moreover, for a long time, the numerical approach had utilized two-dimensional models providing vertical sections transverse to the geostrophic wind. These models present some advantages (short computation time and high resolution) but also one major drawback: A single solution for all kinds of dynamic instabilities, which consists of rolls roughly parallel to the geostrophic wind. This problem is now overcome with three-dimensional large-eddy simulation (LES) that associates each type of instability case to a particular result (Lohou et al., 2000; Moeng and Wyngaard, 1984).

Coherent structures are a physical phenomenon of major importance because they are large-scale movements that cause enhancements in the horizontal fields of thermodynamic and dynamic parameters. In fact, previous observational studies have shown, in cases of organization such as rolls, that the ascending and descending branches of these mechanisms contribute to the vertical transport of heat and moisture across the ABL (Chou and Ferguson, 1991). This means that the vertical fluxes within the ABL result from both turbulence and coherent structures. This double contribution is not explicitly considered in classical parameterisations.

The long term goal of the TRAC (Turbulence Radar Aircraft Cells) program is to try to solve this problem by proposing a parameterization of coherent-structure contributions to the vertical fluxes. This research program was conceived in two steps: the TRAC93 campaign, followed by TRAC98. Lohou et al. (1998a) describe TRAC93, which provided an important advance in the TRAC program goal in that an objective scheme has been developed to identify the organization of the ABL (Lohou et al., 1998b). The numerical approach (Lohou et al., 2000) was limited due to a lack of experimental data - in particular the boundary conditions of the simulated domain and mesoscale divergence information. The TRAC98 campaign, the subject of this paper, has been conducted to address this problem, using a large experimental deployment. This field experiment took place in the central part of the Beauce plain (Figure 1), as for TRAC93, between 11 June and 3 July 1998. This plain is one of the largest and most homogeneous in France, and is thus particularly favourable for the investigation of organized structures in the ABL. 

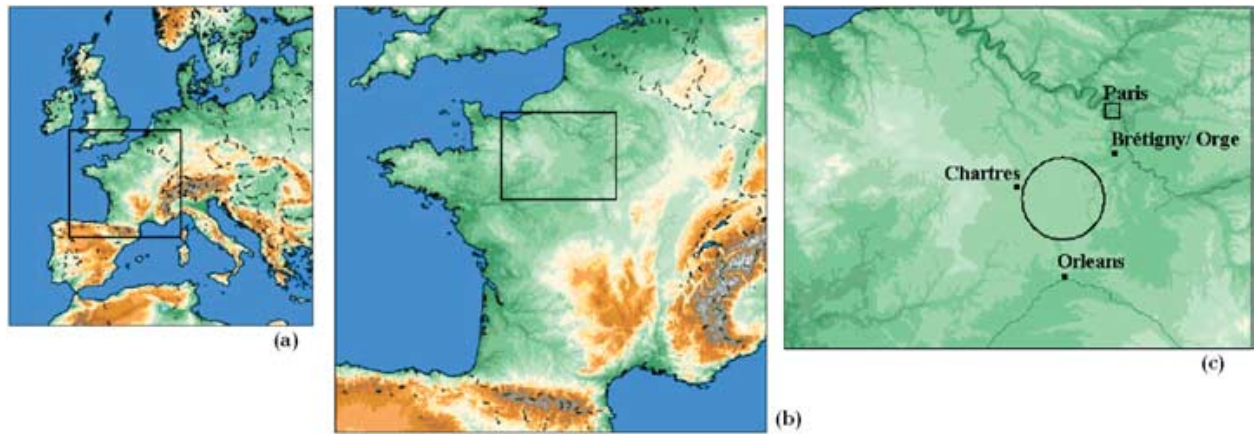

Figure 1. TRAC98 experiment site represented with a zoom from (a) Europe map (about 3600 km west-east), (b) France map (about $1200 \mathrm{~km}$ west-east) and (c) the Beauce plain area (300 km west-east) where the experimental site is indicated by a $30-\mathrm{km}$ radius circle.

Several measurement platforms were deployed during TRAC98 but we based our study essentially on the two-dimensional (2D) data provided by the aircraft. The aim of this paper is to propose a methodology to diagnose the occurrence of organized structures from aircraft data. In contrast with several authors who studied mesoscale organizations linked to cold-air outbreaks or cloudy boundary layers (Agee and Gilbert, 1989; Miura, 1986, Brümmer, 1999), we focussed our study on organisations in clear air or in the slightly cloudy ABL. We want to show that apparently homogeneous boundary layers can display an internal organization that may also alter their characteristics and transfers. So, after a brief presentation of the campaign, aircraft instrumentation and environmental conditions (Section 2), the paper is structured so as to show that the boundary layers we will study can apparently merge well into the statistics of homogeneous boundary layers quoted in the literature (Section 3). Nevertheless, if a classification is applied according to the sampling direction with respect to the wind, some differences appear and a preferred direction can be determined which gives an indication of organization (Section 4). Finally, a specific analysis is presented in Section 5 for one flight which is noteworthy for the consistency of the results obtained by the sampling direction approach. The study will be completed by a cloud cover analysis, the clouds being in this case good tracers of the ABL organization. Then, a correlation analysis is performed in order to characterise, on the one hand, the relationship between parameters supposed to be indicators of coherent structure occurrence and to extract, on the other hand, length scales linked to these physical mechanisms. 


\section{Experimental Context}

\subsection{EXPERIMENTAL SET UP}

Most of the data used in this paper are from the aircraft. We describe nevertherless the overall environment used to define the experimental conditions. It was deployed as described in Figure 2, with the Ronsard C-band radar in the center of a nearly equilateral triangle of about $37 \mathrm{~km}$ side length and a network of UHF and sodar profilers at the triangle vertices. In addition, a two-dimensional description was provided by ground-based meteorological stations (denoted by SM) and a ground-based turbulent network of 5 masts, oriented north-south and east-west and situated at the main ground station (denoted by PS) (see Figure 2). Rawinsoundings as well as a tethered balloon provided an additional view of the ABL structure. Finally, airborne measurements enabled description of the ABL in two perpendicular directions, crossing over the PS site.

In this paper, we will use, in addition to the aircraft measurements, the mean conditions and energy balance results from the ground station at the PS site, the boundary-layer height and vertical structure information provided by the rawinsoundings and some wind information provided by the Ronsard radar (Jacoby-Koaly et al., 2002).

\subsection{AIRBORNE MEASUREMENTS}

Two aircraft participated to the TRAC98 experiment: The Merlin IV (MIV) from Météo-France and the ARAT (Avion de Recherche Atmosphérique et de Télédétection) Fokker 27 from the Institut National des Sciences de l'Univers, the Institut Géographique National, the Centre National d'Etudes Spatiales and Météo-France.

\subsubsection{Flight Plan}

The ARAT30 flight plan is presented in Figures $3 \mathrm{a}$ and $3 \mathrm{~b}$ as an example of the standard flight plan. It was chosen to provide a vertical description of the ABL. Therefore, it consisted in performing soundings (1 to 3) above the PS location or above the RONSARD site. The flight plan then covered two vertical perpendicular planes that intersect above PS. Within each plane, the aircraft performed $50 \mathrm{~km}$ legs at different levels. These levels were chosen with respect to the boundary-layer height, $Z_{i}$. The planes orientation was chosen so that one of the two planes was in the ABL mean wind direction provided by the radar or by the rawinsoundings. When the wind was weak, the vertical planes were oriented along the axes of the turbulence network at PS, that is to say north-south, and east-west. As the wind was quiet or blowing either from the west or from the north (see Section 2.3), these preferential directions turned out to fit all flight configurations. 

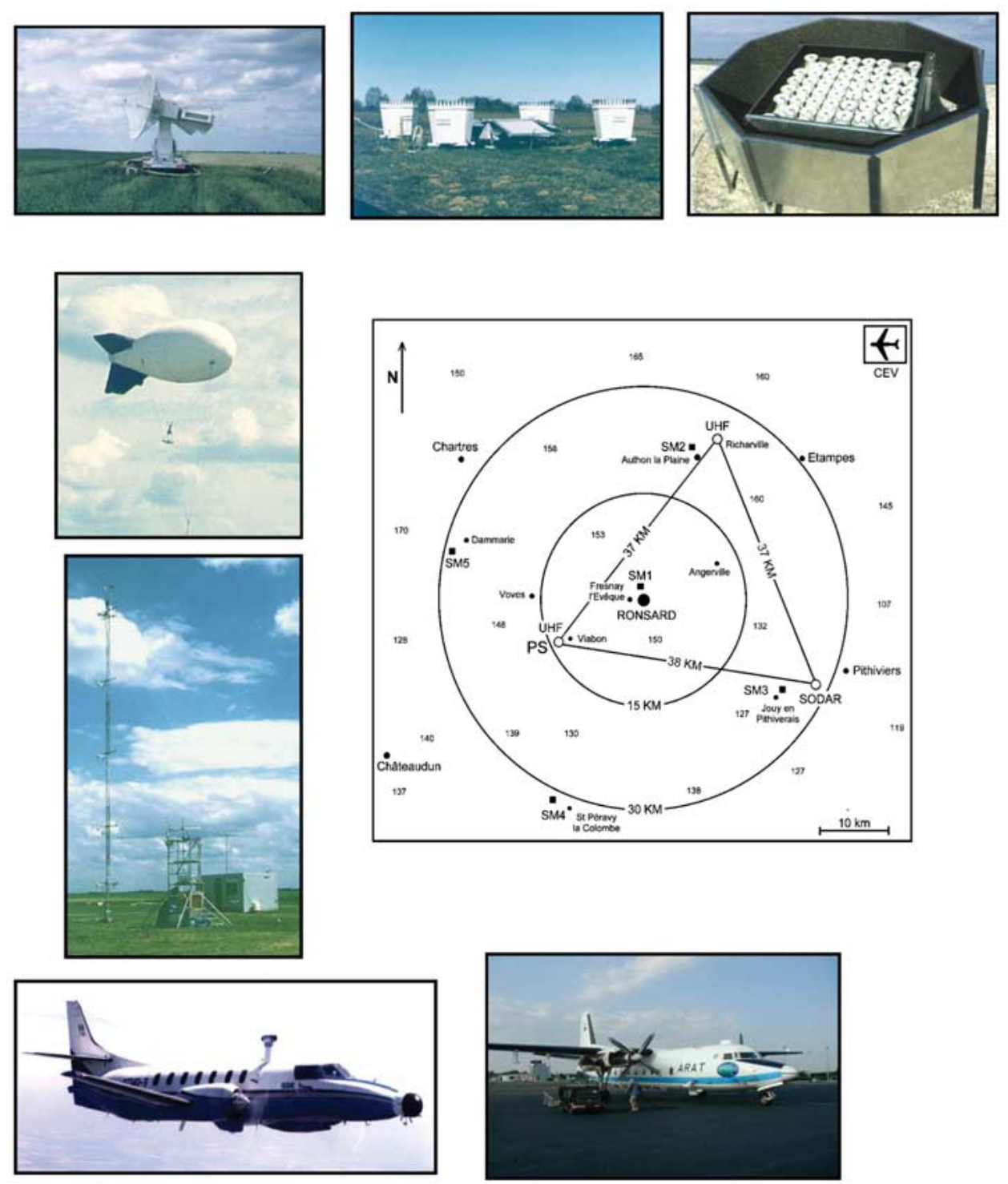

Figure 2. Layout of the different measurement platforms over the Beauce plain during the TRAC98 experiment. The RONSARD radar is at the centre of the deployment. Two circles centered on the RONSARD position indicate two areas of $15 \mathrm{~km}$ and $30 \mathrm{~km}$ radius. Three wind profilers are situated at the vertices of a quasi equilateral triangle, being itself within the RONSARD exploration domain. At the PS site, a sodar, a RASS system as well as a network of five instrumented towers were also deployed. The symbols SM followed by a number ranging from 1 to 5 indicate the position of five ground-based meteorological stations. At the top, the pictures illustrate from left to right: the RONSARD radar, one UHF and the RASS system together, and a sodar. On the left hand side and from top to bottom, the pictures illustrate: the tethered balloon and the central mast at the PS site. At the bottom, the pictures illustrate the Merlin IV and the ARAT Fokker 27. 

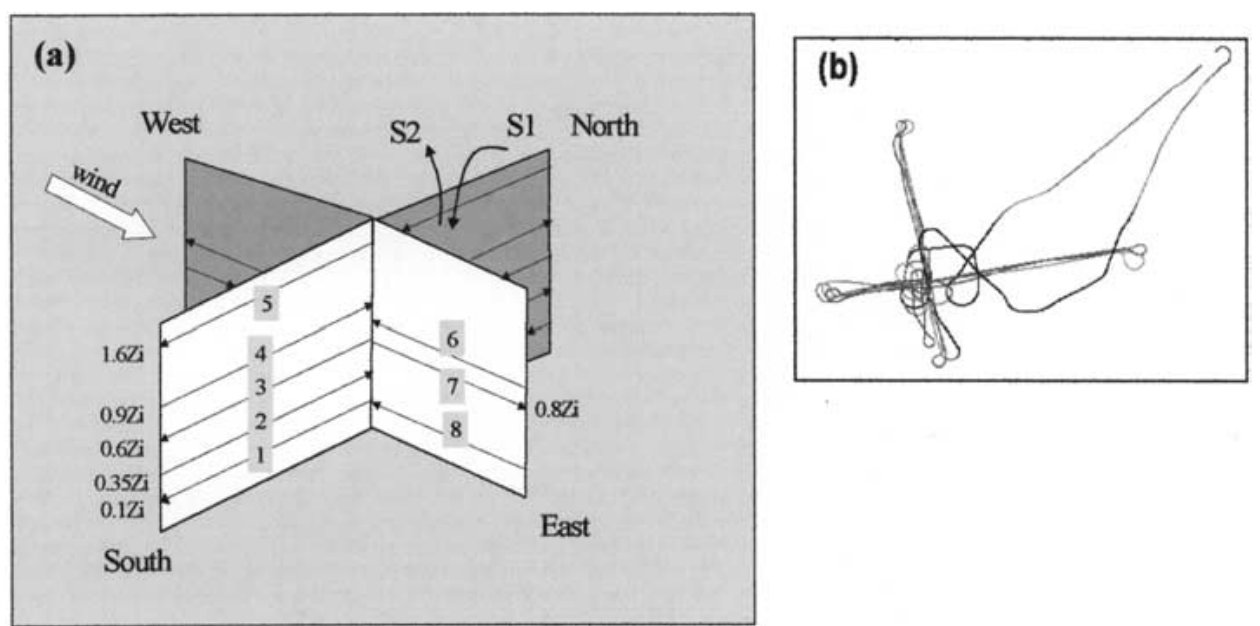

Figure 3. An example of the flight plan performed by the aircraft during the TRAC 98 experiment (ARAT30). (a) three-dimensional view, (b) horizontal track. $Z_{i}$ is the boundary-layer height. S1 and S2 descending and ascending arrows are for descending and ascending vertical soundings. The west-east plane is alongwind on this day.

\subsubsection{Aircraft Equipment}

Both aircraft measured the same parameters with slightly different equipment. They are equipped with a radome that measures the attack and sideslip angles (Brown et al., 1983). The temperature is measured by a Rosemount 102E2-AL probe and the water vapour content by an AIR Lyman-alpha hygrometer with a GE1011B dew-point hygrometer as a reference. An inertial navigation system (SAGEM Ulis 45i) inside both aircraft provided the horizontal geographical position, the ground velocity and the attitude angles of the aircraft.

The static air temperature was computed from the measured impact temperature after correction for adiabatic heating around the sensor due to the aircraft airspeed. The true airspeed was deduced from the dynamic pressure. The wind was obtained as the sum of the groundspeed and true airspeed vectors. The vertical wind velocity along the legs was computed using the airplane equations of motion with the simplifications proposed by Lenschow (1986).

The fast data, recorded at a rate of $64 \mathrm{~Hz}$ and $50 \mathrm{~Hz}$, and processed at $16 \mathrm{~Hz}$ and $25 \mathrm{~Hz}$ on the Fokker 27 and Merlin IV respectively, were used to calculate the turbulent fluxes of sensible heat $(\mathrm{H})$ and latent heat (LE).

Net radiation, $\mathrm{Rn}$, was calculated from the measurement of its four radiative components. The incoming and outgoing shortwave radiation Si and So were measured using Eppley pyranometers and the equivalent longwave radiation $\mathrm{Li}$ and $\mathrm{Lo}$ with Eppley pyrgeometers:

$$
\mathrm{Rn}=\mathrm{Si}+\mathrm{So}+\mathrm{Li}+\mathrm{Lo} .
$$




\subsubsection{Calculation Method for Turbulence Parameters}

At each horizontal and stabilized leg are associated temporal series of different parameters. Each instantaneous value is the sum of a mean value that characterizes the complete leg and a fluctuating value,

$$
x=\bar{x}+x^{\prime} .
$$

The data marked with a bar correspond to mean data. The collected data allowed computation of second- and third-order moments, among which are the heat fluxes, using the eddy-correlation method. Two sets of data are available for these moments: the first one uses a rough series corrected for the average and linear trend, the second one is obtained after a high pass filtering that aimed at removing the drifts induced by larger scales. This filtering is applied with a cut-off frequency of $0.018 \mathrm{~Hz}$, which corrresponds to a length scale close to $5 \mathrm{~km}$. The comparison between the two sets of data allows the evaluation of the high-pass filtering effect (see next subsection). The latent heat flux includes the Webb correction (Webb et al., 1980).

The airborne data are usually analyzed through a statistical approach. This method consists in parameterising the data of all the flights of a measurement campaign in order to be able to represent them in the form of vertical profiles that fit universal laws. To be able to discuss the variability in the moment profiles, a preliminary study of their accuracy is required.

\subsubsection{Estimation Errors}

Three types of errors are involved in the turbulent moment estimations: The error linked to the sensor accuracy, the systematic error and the random error. The last two are linked to the use of the eddy-correlation method to compute fluxes.

According to Hildebrand (1991), it has been assumed that the error linked to sensor accuracy, which is dependent on the calibration procedures and sampling rate, can be held within $5-10 \%$.

The effect of the loss due to high-pass filtering was estimated as the difference between the non-filtered (NFD) and the filtered (FD) values, this difference being expressed as a percentage of the non-filtered value:

$$
\frac{N F D-F D}{N F D}=F L(\%) \text {. }
$$

In addition to the estimation of errors, this parameter will be used in Section 4 as a criterion to study the anisotropy of the ABL.

Figure 4 represents the profiles of the loss due to filtering versus the normalized altitude $Z / Z_{i}$ for both $\mathrm{H}$ and LE fluxes and for the various flights. The FL values are generally positive, which shows that the filtering leads to a loss in the majority of cases. The filtering loss values for the sensible heat flux indicate a tendency to increase with altitude from the surface and up to the $0.9 Z_{i}$ level. This behaviour 


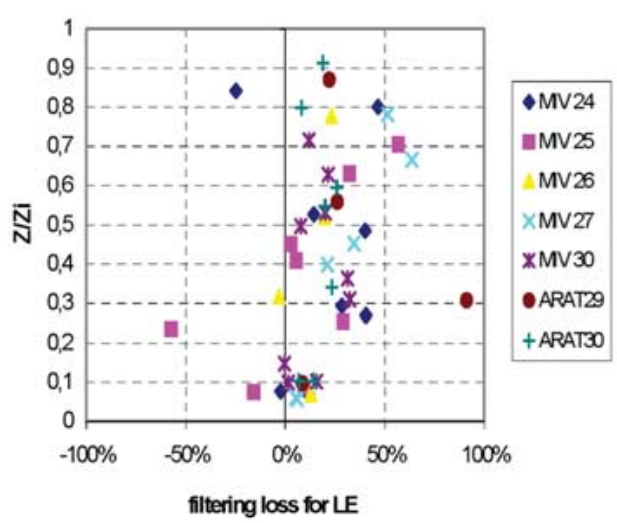

(a)

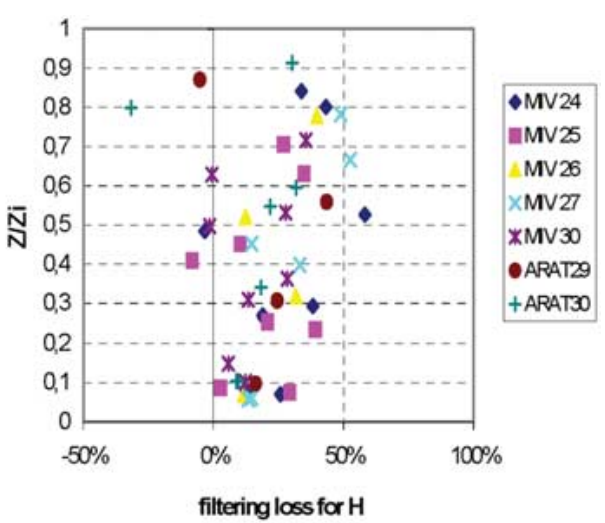

(b)

Figure 4. Vertical profiles of the filtering loss for the latent (a) and sensible (b) heat fluxes deduced from the data collected by the aircraft during the seven flights of the TRAC98 experiment.

\section{TABLE I}

For three specific heights, indicated in the first column, the loss due to filtering is estimated through the parameter FL for the sensible and latent heat fluxes. Another estimation of the filtering loss is given through the $\varepsilon_{s}$ parameter, the systematic error: specified for any scalar flux. The last two columns indicate the random error, noted $\varepsilon_{r}$, for the sensible and latent heat fluxes. The symbol $\rightarrow$ means 'tends towards'.

\begin{tabular}{llllll}
\hline$Z / Z_{i}$ & $\begin{array}{l}\text { Sensible heat } \\
\mathrm{FL}(\%)\end{array}$ & $\begin{array}{l}\text { Latent heat } \\
\mathrm{FL}(\%)\end{array}$ & $\left(\varepsilon_{s}(\%)\right.$ & $\begin{array}{l}\text { Sensible heat } \\
\left(\varepsilon_{r}(\%)\right.\end{array}$ & $\begin{array}{l}\text { Latent heat } \\
\left(\varepsilon_{r}(\%)\right.\end{array}$ \\
\hline 0.8 & 35 & 25 & 19 & $\rightarrow 100$ & 20 or greater \\
0.5 & 25 & 20 & 15 & 22 & 20 \\
0.1 & 15 & 10 & 7 & 10 & 11 \\
\hline
\end{tabular}

also seems to be verified for the latent heat flux. Mean values of the filtering loss are reported for three levels in Table I.

The FL parameter constitutes a direct estimation of the loss due to filtering, also called systematic error. On the other hand, Mann and Lenschow (1994) proposed an empirical relation to estimate this error:

$$
\varepsilon_{S}=b Z_{i}\left(\frac{Z}{Z_{i}}\right)^{1 / 2}\left(\frac{1}{L_{c}}-\frac{1}{L}\right)
$$

where $L_{c}$ is the cut-off wavelength of the high-pass filter, $L$ the sample length, $Z_{i}$ the ABL height and $b$ is equal to 1.2. The systematic error was calculated for three flight levels from Equation (4). The results are presented in Table II. Averaged values of $Z_{i}, L$ and $L_{c}$ were taken as $1 \mathrm{~km}, 50 \mathrm{~km}$ and $5 \mathrm{~km}$ respectively. 


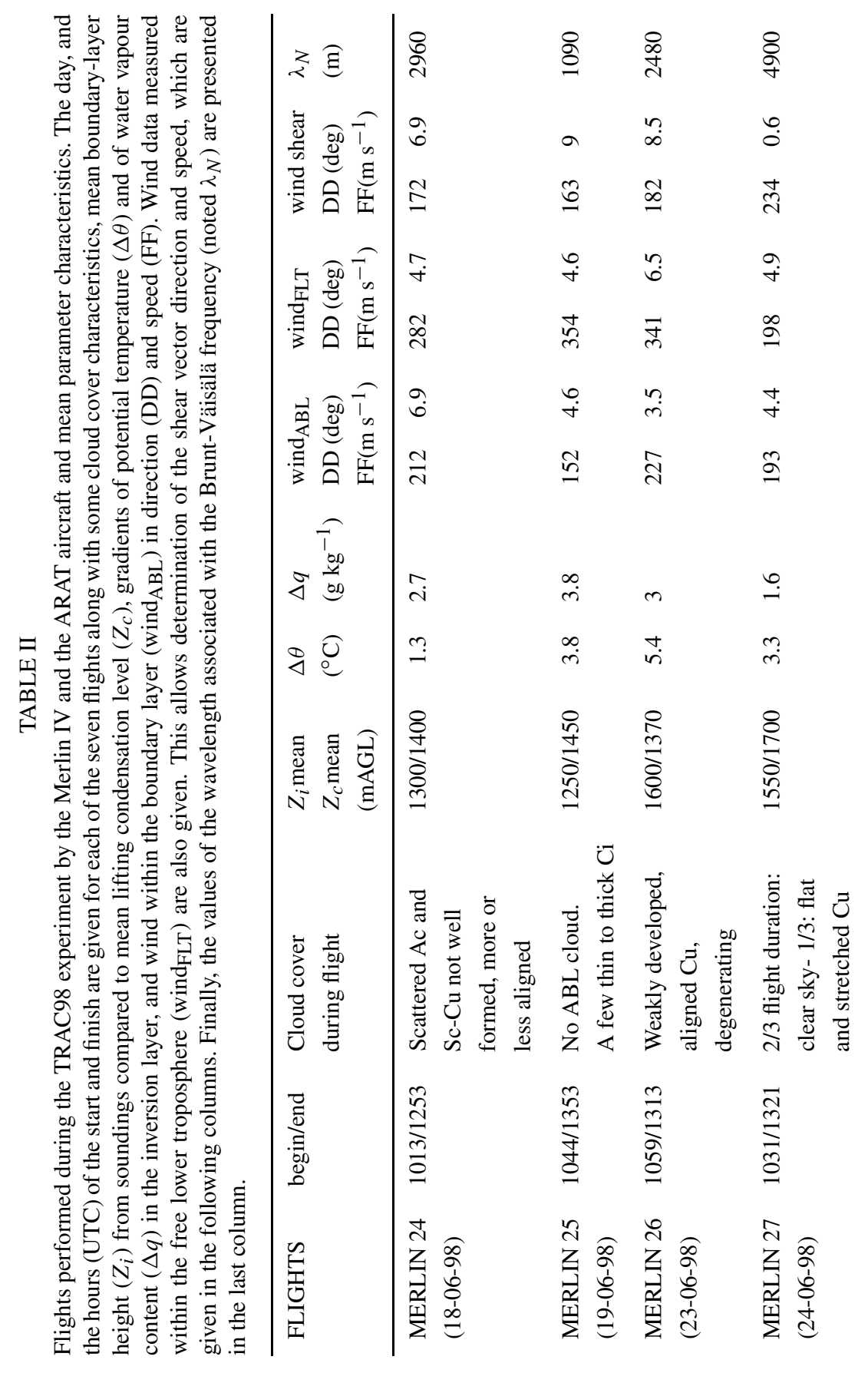




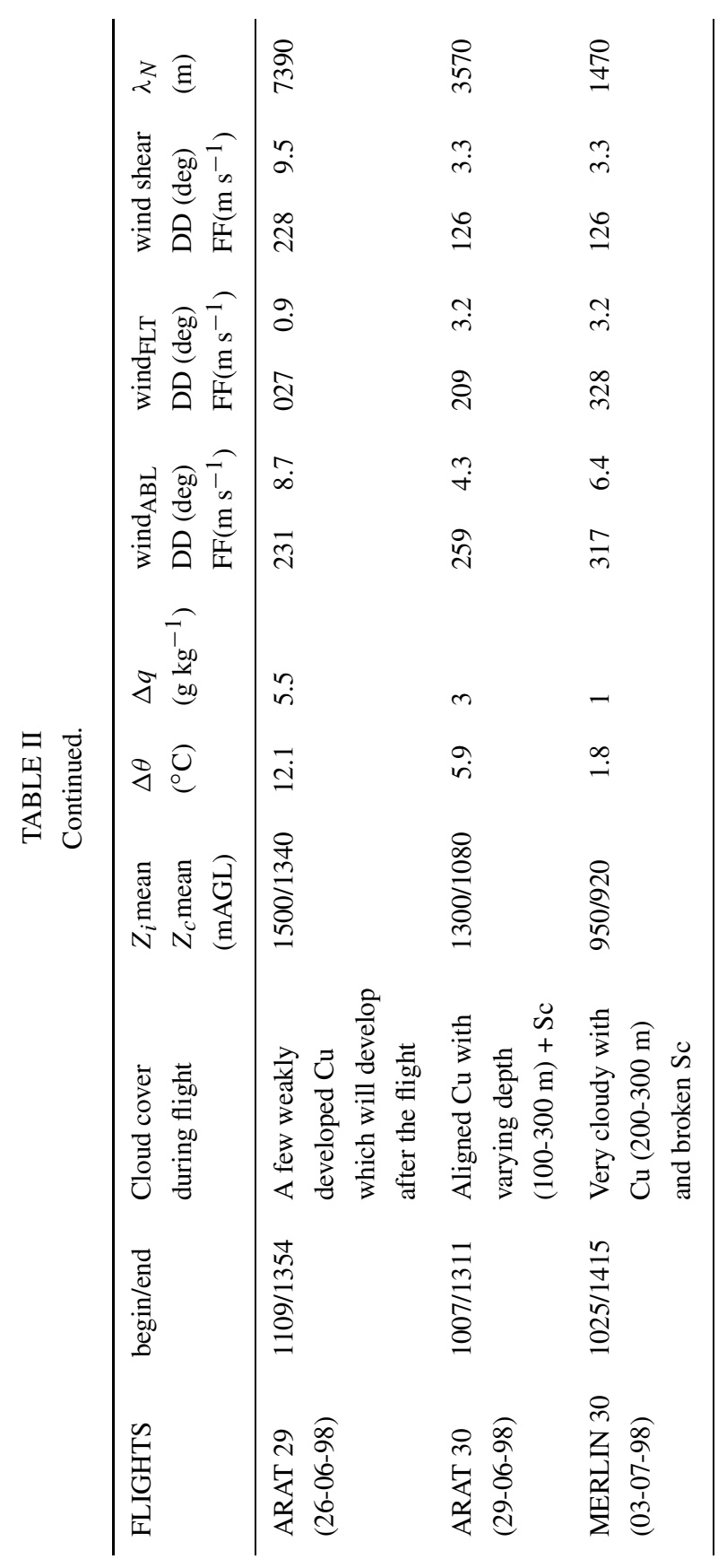


The orders of magnitude of the loss due to filtering, obtained in a direct way with the FL parameter as well as using the empirical formulation (4), are similar to the literature results (Mann and Lenschow, 1994).

The last type of error is the random error, $\varepsilon_{r}$. It is linked to the fact that the flight leg is a single sample of a random process. Wyngaard (1983) proposed a parameterization of $\varepsilon_{r}$ :

$$
\varepsilon_{r}=\left[\frac{2 l_{w a}}{L}\left(1+r_{w a}^{-2}\right)\right]^{1 / 2},
$$

where $l_{w a}$ is the integral length scale corresponding to the first maximum of the integral of the autocorrelation function between vertical velocity $w$ and scalar $a$, $r_{w a}$ the correlation coefficient and $L$ the sample length. The random error expresses the scatter that would be obtained for numerous realizations of the flux, keeping $L$ as the sample length.

Table I presents estimations of $\varepsilon_{r}$ for latent heat and sensible heat fluxes derived from airborne data collected during TRAC98. For both turbulent fluxes, the random error increases from the surface up to the ABL top. At $0.8 Z_{i}, \varepsilon_{r}$ values for LE reach $20 \%$ or go on increasing whereas $\varepsilon_{r}$ values for $\mathrm{H}$ tend towards $100 \%$, which was expected since the flux is close to zero at this level.

If the three kinds of error are compared, the main one appears to be the random error which is directly linked to the sampling process and cannot be avoided.

\subsection{Meteorological EnVironment}

The experimental conditions during TRAC98 were desired to be anticyclonic. In fact, such a situation maintains the relatively stationary meteorological conditions that are necessary for the flow within the ABL to have time to organize. Moreover, at the beginning of the summer, when anticyclones prevail over France, they are generally centered over central Europe bringing France a north-north-easterly flow. On the other hand, the ground-based measurement network was installed so that the fetch is maximum for a dominant circulation coming from north. Figure 5 shows that the Beauce plain has not systematically experienced the required meteorological conditions during the experimental campaign. In fact, the compass card that concerns the TRAC98 conditions points out two regimes:

- The north regime: Linked to the anticyclone occurrence providing fair weather conditions over the Beauce plain site. This regime prevailed at the end of the experiment ( 1 and 2 June).

The south-west regime: For that case, the wind direction varies, on average, between $200^{\circ}$ and $260^{\circ}$ for the whole campaign. This regime is associated either with anticyclonic conditions conducive to fair weather conditions with few clouds (23 and 24 June) or with cyclonic conditions bringing more or less clouds at different levels (26, 29 June and 3 July). 


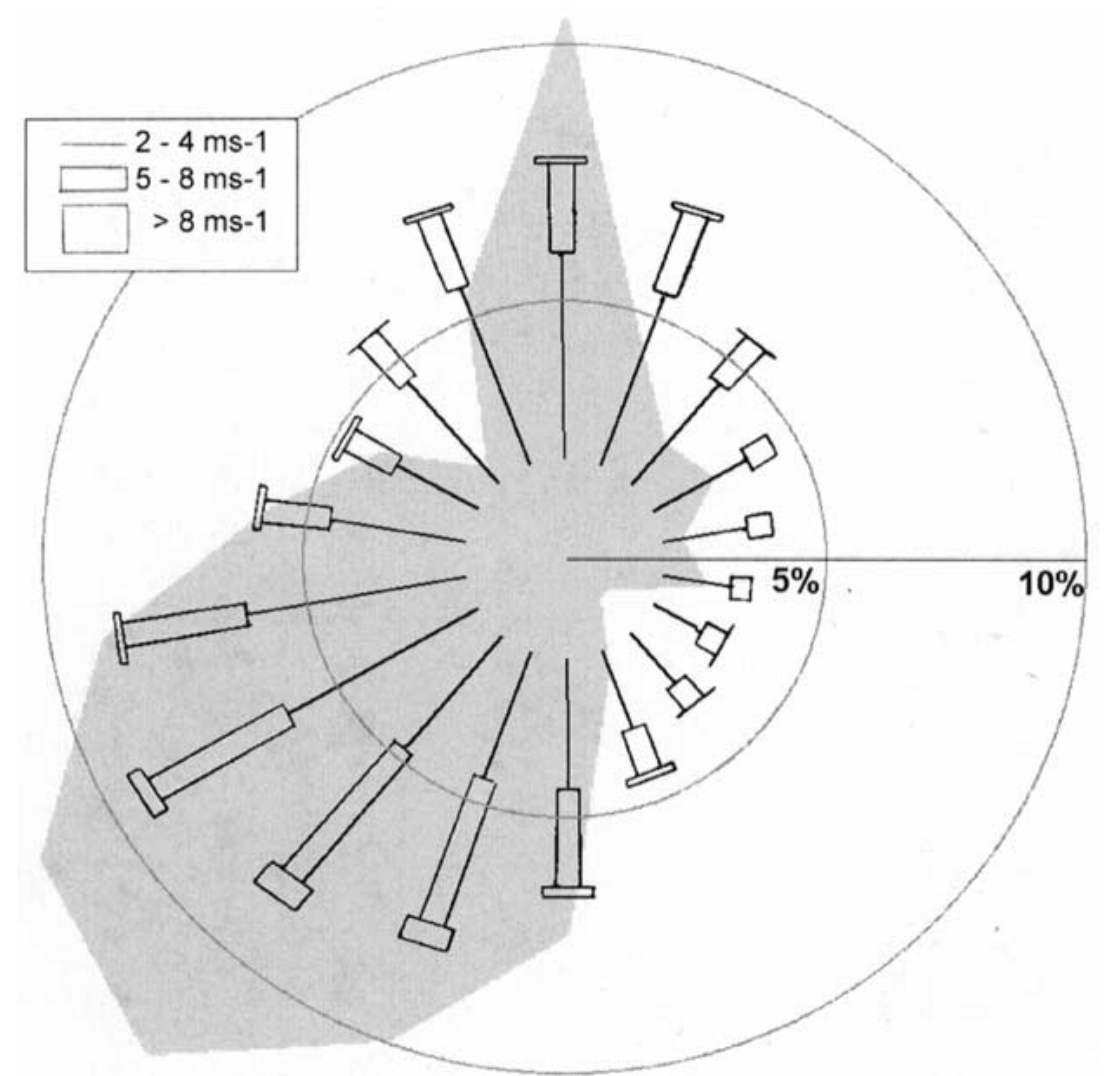

Figure 5. Wind rose: The black lines are linked to the statistics established for Chartres city (shown on Figure 2) from data collected during 10 years. The line thickness is linked to the wind speed and the line length to the frequency occurrence indicated by the circles (in percent). The grey colour is related to wind measurements performed during the TRAC98 experiment at the central mast situated at the PS site and is a frequency of occurrence as well. The direction is the direction from which the wind comes.

Finally, almost half of the days corresponding to airborne operations are affected by slightly disturbed meteorological conditions. During the other days, the experimental area could be affected by some fair weather ABL cumuli.

The day and hour of flights performed during TRAC 98 are summed up in Table II along with some parameters characteristic of the ABL. From the thermodynamic measurements performed by the aircraft, the evolution of $Z_{c}$, the lifting condensation level along the trajectory, has been determined. This height has been compared to the mean $Z_{i}$ obtained from aircraft soundings or radiosoundings and was found to be essentially the same. In fact the vertical development of the clouds was limited, as depicted in Table II. So we will assume in the following that clouds do not significantly affect the dynamics of the $\mathrm{ABL}$ and that $Z_{c}=Z_{i} . Z_{c}$ provides in this way, an accurate estimation of the mixing height for each flight leg (usually $Z_{i}$ is 
derived from the radiosounding information and is not always representative of the spatial or temporal variability).

The jumps of potential temperature $(\Delta \theta)$ and mixing ratio $(\Delta q)$, associated with the inversion layer capping the ABL, have also been determined from rawinsoundings performed at the PS site at 1200 UTC. The strongest value of both gradients correspond to the ARAT 30 flight. This indicates that entrainment has probably affected the $\mathrm{ABL}$ in a more important way during this flight than during the others.

Table II gives wind within the $\mathrm{ABL}$ ( wind $_{\mathrm{ABL}}$ ) and within the free lower troposphere (FLT, wind FLT $_{\text {) }}$. They correspond to mean values of the direction and speed obtained, for each flight, from vertical profiles deduced from the RONSARD data. The shear vector is obtained as the difference between the FLT wind and the wind within the ABL. This shear vector and the mean wind within the ABL are two important parameters in our study because, in the literature, the preferred direction of organized structures was shown to be parallel to one of these two vectors (Lohou et al., 1998b). The results indicate the occurrence of a west-south-westerly wind during all flights except for the MERLIN 25 flight. On the other hand, the wind was generally weak, less than $5 \mathrm{~m} \mathrm{~s}^{-1}$. Note that ARAT 30 flight, which will be analyzed more precisely in next sections, is characterized by a westerly wind $\left(259^{\circ}\right)$, and a shear vector $47^{\circ}$ apart $\left(126^{\circ}-306^{\circ}\right)$.

The Brunt-Väisälä frequency is also calculated for each flight. It is defined as:

$$
N^{2}=\left(\frac{g}{T}\right) \frac{\partial \theta}{\partial z}
$$

where $\frac{\partial \theta}{\partial z}$ is the potential temperature gradient, $T$ the mean temperature and $g$ the gravitational acceleration. The first two parameters have been estimated within the stable layer above the ABL from the rawinsoundings performed at midday above the experimental field. This layer is at least $500 \mathrm{~m}$ deep. The length scale associated with this frequency is determined by:

$$
\lambda_{N}=\frac{2 \pi \operatorname{wind}_{F L T}}{N} .
$$

Its values are reported in Table II. The Brunt-Väisälä frequency informs us about the wavelength or the frequency of possible gravity waves, which is relevant to studies dealing with coherent structures. For the ARAT 30 flight, in particular, the $\lambda_{N}$ value will be compared, in the following, to the lengthscales deduced from the airborne data analysis.

The local meteorological conditions are also characterized by parameters whose temporal evolution during TRAC98 is shown in Figure 6. These values have been obtained at the central mast of the PS site.

The net radiation $(\mathrm{Rn})$ indicates that the experimental area has been affected by an evolving cloud cover during the experiment. For the first three days, the clouds are almost non-existent whereas they are numerous for June 21 and 22. June 30, 


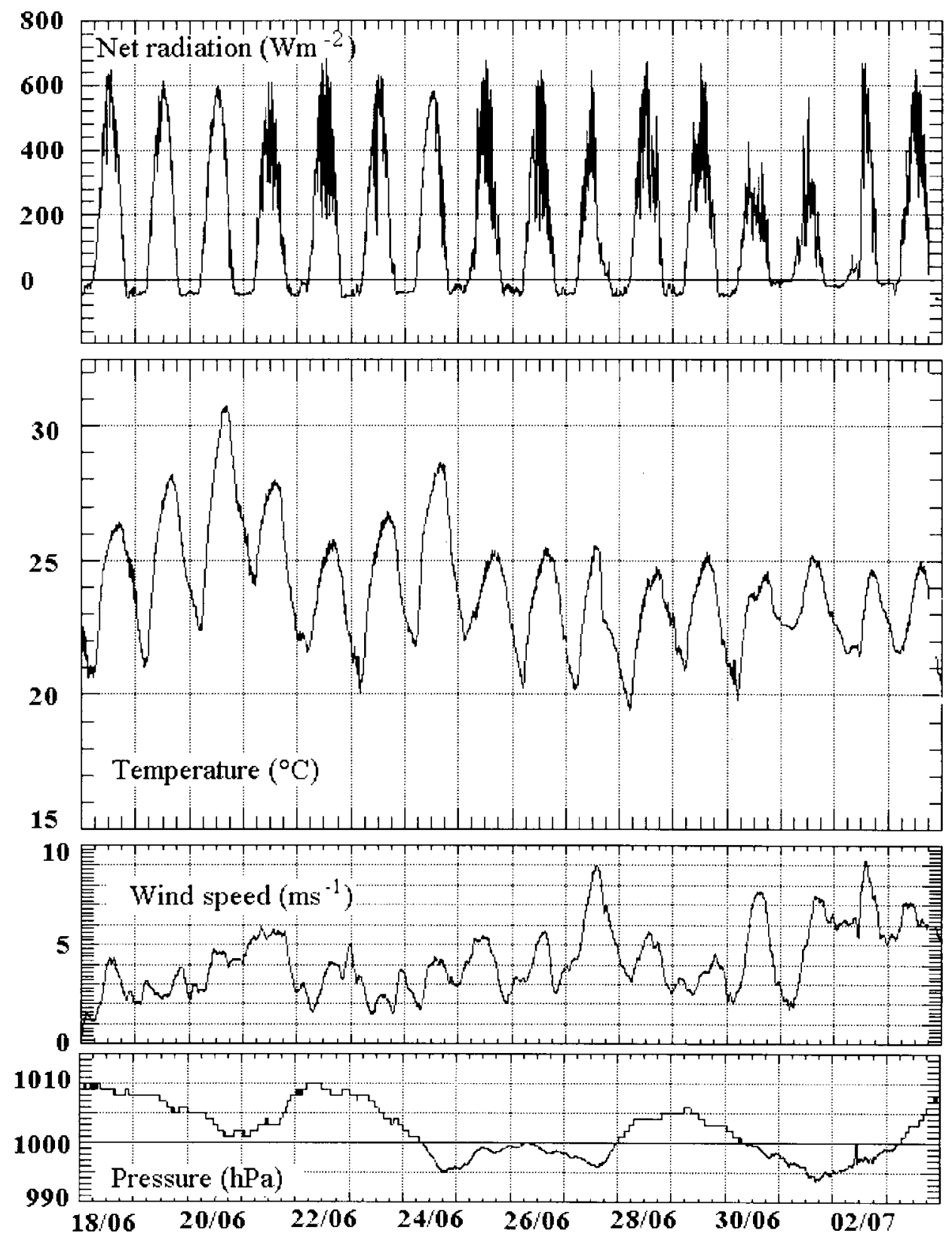

Figure 6. Temporal series of four parameters during the whole TRAC98 experiment; from top to bottom: the net radiation $\left(\mathrm{W} \mathrm{m}^{-2}\right)$, temperature $\left({ }^{\circ} \mathrm{C}\right)$, wind speed $\left(\mathrm{m} \mathrm{s}^{-1}\right)$ and pressure $(\mathrm{hPa})$. They were measured at $10 \mathrm{~m}$ on the central mast of the instrumented towers network deployed at the PS site. 
July 1 and 2 encountered a stratiform cloud cover leading to an important decrease of the maximum value of $\mathrm{Rn}$ and of its amplitude over the diurnal cycle. The flight days were outside these cloudy periods.

\subsection{SURFACE ENERGy BUdGET}

The surface energy budget is described by the following equation:

$$
\mathrm{Rn}=\mathrm{Hs}+\mathrm{LEs}+\mathrm{G},
$$

where $\mathrm{Rn}$ is the net radiation, Hs and LEs the sensible and latent surface heat fluxes, and $\mathrm{G}$ the soil heat flux.

The airborne data provide a direct estimation of Rn, Hs and LEs. The soil heat flux is then deduced from the energy budget balance. The surface sensible heat flux is obtained by extrapolating the $\mathrm{H}$ profile down to the surface for each vertical plane. For the latent heat flux, the $0.1 Z_{i}$ data are assumed to be surface values due to the difficulty of extrapolating the profiles (too much scatter). The results are reported in Table III for the various vertical planes of each flight.

The surface latent heat flux is systematically higher than the sensible heat flux, except for the MERLIN 30 flight; they are in the range 170-400 $\mathrm{W} \mathrm{m}^{-2}$. On the other hand, it has to be observed that the data variability between vertical planes of a same flight is more important for LE than for $\mathrm{H}$. The greatest difference, for the latent heat flux, is associated with MERLIN 30 flight and is estimated at $34 \%$. The net radiation varies between 450 and $610 \mathrm{~W} \mathrm{~m}^{-2}$, and in opposition to LE, its values are little different from one plane to the other.

The most important remark that can be made from the results of Table III concerns the soil heat flux: It is considerably higher than $100 \mathrm{~W} \mathrm{~m}^{-2}$, except for three cases that are marked with the symbol $>$. This threshold of $100 \mathrm{~W} \mathrm{~m}^{-2}$ is the maximum of $\mathrm{G}$ expected for homogeneous and temperate areas like the Beauce plain. Note that $54 \%$ of the values presented in Table III exceed $150 \mathrm{~W} \mathrm{~m}^{-2}$. This means that the soil heat flux deduced from the energy budget balance with airborne data is frequently overestimated. This overestimation is logically explained by the underestimation of heat fluxes as the net radiation values are consistent with the local seasonal characteristics. With airborne data, it is difficult to quantify this underestimation as the soil heat flux measurement is not directly accessible. Nevertheless, the literature indicates that $\mathrm{G}$ can be expressed as a fraction of $\mathrm{Rn}$ that depends on the plant cover type and on the soil humidity content (Verhoef, 1995; Barr et al., 1997). For the TRAC98 experiment, we use a ratio of 0.1 that is suitable for the cultivated and irrigated area represented by the Beauce plain. Considering this soil heat flux value, the sum of the sensible and latent heat fluxes represents $90 \%$ of the net radiation. Then, the underestimation of the airborne heat fluxes measured during TRAC98 is quantified by:

$$
0.9 \mathrm{Rn}-(\mathrm{Hs}+\mathrm{LEs})=\mathrm{U},
$$


TABLE III

Aircraft energy budget: The energy fluxes are the surface values of the sensible (Hs) and latent (Les) heat fluxes, and of the net radiation (Rn) measured by aircraft. The ground heat flux $(\mathrm{G})$ is deduced from these three parameters using the energy budget equation given in the text. For each flight, these values were estimated for each vertical plane described by the aircraft, which is why 1 to 3 line(s) is(are) used to describe a flight. The symbol $>$ in the column relative to $G$ points out the results less or equal to $100 \mathrm{~W} \mathrm{~m}^{-2}$. Last column: The $\mathrm{U}$ parameter refers to the underestimation of the sensible and latent heat fluxes. The orientation of the flight leg relative to the wind ( $\perp$ : Crosswind, //: Along wind) or to the ground (N-S for north-south and E-W for east-west) is also indicated.

\begin{tabular}{|c|c|c|c|c|c|c|}
\hline FLIGHTS & $\begin{array}{l}\text { Leg } \\
\text { orientation }\end{array}$ & $\begin{array}{l}\text { Hs } \\
\left(\mathrm{W} \mathrm{m}^{-2}\right)\end{array}$ & $\begin{array}{l}\text { LEs } \\
\left(\mathrm{W} \mathrm{m}^{-2}\right)\end{array}$ & $\begin{array}{l}\mathrm{Rn} \\
\left(\mathrm{W} \mathrm{m}^{-2}\right)\end{array}$ & $\begin{array}{l}\mathrm{G} \\
\left(\mathrm{W} \mathrm{m} \mathrm{m}^{-2}\right)\end{array}$ & $\begin{array}{l}\mathrm{U} \\
\left(\mathrm{W} \mathrm{m}^{-2}\right)\end{array}$ \\
\hline MERLIN 24 & $\perp$ & 90 & 310 & 570 & 170 & 113 \\
\hline$(18-06-98)$ & // & 80 & 290 & 610 & 240 & 179 \\
\hline MERLIN 25 & E-W & 90 & 400 & 590 & $>100$ & 41 \\
\hline (19-06-98) & $\mathrm{N}-\mathrm{S}$ & 60 & 270 & 590 & 260 & 201 \\
\hline $\begin{array}{l}\text { MERLIN } 26 \\
(23-06-98)\end{array}$ & $\perp$ & 140 & 240 & 520 & 140 & 88 \\
\hline MERLIN 27 & $\mathrm{~N}-\mathrm{S}$ & 110 & 200 & 590 & 280 & 221 \\
\hline (24-06-98) & E-W & 100 & 260 & 590 & 230 & 171 \\
\hline $\begin{array}{l}\text { ARAT } 29 \\
(26-06-98)\end{array}$ & $\perp$ & 120 & 250 & 490 & 120 & 71 \\
\hline ARAT 30 & $\perp$ & 130 & 190 & 450 & 130 & 85 \\
\hline (29-06-98) & // & 180 & 210 & 470 & $>80$ & 33 \\
\hline MERLIN 30 & $\perp$ & 180 & 170 & 530 & 180 & 127 \\
\hline \multirow[t]{2}{*}{ (03-07-98) } & I & 170 & 170 & 540 & 200 & 146 \\
\hline & $\perp$ & 210 & 260 & 540 & $>70$ & 16 \\
\hline
\end{tabular}

where Hs + LEs is the sum of both heat flux values given in Table III. The underestimation $\mathrm{U}$ is also reported in the table. It varies between 16 and $221 \mathrm{~W} \mathrm{~m}^{-2}$, the maximum value being associated with the MERLIN 27 flight. This underestimation of the heat fluxes has often been encountered in experimental studies. Some hypotheses have been considered, such as the filtering loss, but there is no consensus about the phenomenon that could be at the origin of the non-closure of the energy budget.

The energy budget has also been analysed from the data collected by the groundbased turbulent mast at the PS site. In this case, all four terms of the budget were available, from net radiation ( $\mathrm{Rn}$ ) and eddy correlation (Hs and LEs) measurements 

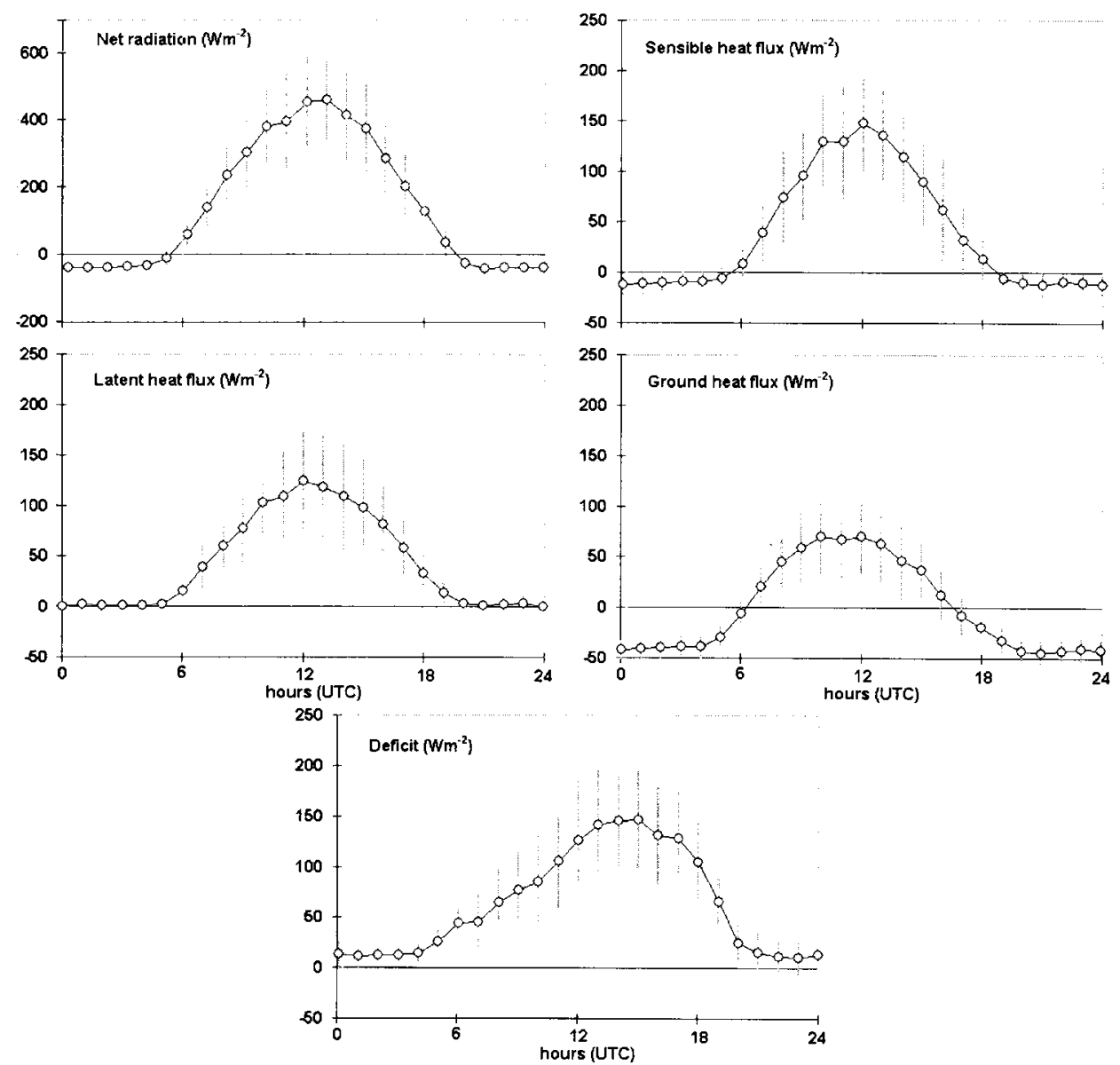

Figure 7. Diurnal cycle determined for five parameters from measurements collected during the whole TRAC98 experiment on the central mast at PS (Figure 2). These parameters are the net radiation, the sensible and latent heat fluxes, the ground heat flux and the deficit. The values given in $\mathrm{W} \mathrm{m}{ }^{-2}$ are hourly averages.

and from temperature measurements at six levels in the ground $(\mathrm{G})$. A mean diurnal cycle, characteristic of the whole TRAC98 campaign, was established for the net radiation, both heat fluxes and the soil heat flux. They are represented on Figure 7. The diurnal cycles are determined from hourly means and the standard deviations are indicated by vertical bars. The latent heat flux shows a diurnal cycle quite similar to that of the net radiation with a maximum around midday. In contrast, the sensible heat flux shows a maximum that is less well marked. The diurnal cycle of the soil heat flux has a phase shift of the maximum towards the end of the morning: in fact, the maximum value of $\mathrm{G}$ is reached at 1000 UTC and remains constant until 1300 UTC. 
The energy budget determined at the ground can be characterized, in a crude way, by the midday mean values of each of the four fluxes: the net radiation is estimated at $500 \mathrm{~W} \mathrm{~m}^{-2}$, the sensible heat flux at $150 \mathrm{~W} \mathrm{~m}^{-2}$, the latent heat flux at $120 \mathrm{~W} \mathrm{~m}^{-2}$, and the ground heat flux at $80 \mathrm{~W} \mathrm{~m}^{-2}$. These four values point out that the energy budget is far from being balanced. We have called deficit (D) the parameter to which is attributed the difference between the left and right hand sides of the budget-equation:

$$
\mathrm{D}=\mathrm{Rn}-\mathrm{LEs}-\mathrm{Hs}-\mathrm{G} \text {. }
$$

A mean diurnal cycle was determined for this term, and is represented in Figure 7. $\mathrm{D}$ is estimated at around $10-15 \mathrm{~W} \mathrm{~m}^{-2}$ during the night whereas, during the day, it reaches a mean maximum of $150 \mathrm{~W} \mathrm{~m}^{-2}$. Moreover, it shows a strong asymmetry, with the maximum deficit around 1400 UTC. This phase shift appears clearly linked to the diurnal behaviour of the soil heat flux.

The underestimation of the latent heat flux is one of the possible explanations for the non-closure of the energy budget. In fact, the measurement area is a regularly cut low fallow, and is not irrigated in opposition to some of the cultivated lands situated in the vicinity. This geographical configuration can induce a dry island effect and leads to an underestimation of the evaporation flux.

This explanation is however no longer relevant in the case of the regional measurements from the aircraft. In fact, our argument is that it is the anisotropy of the boundary layer (that will be pointed out in the next sections) that prevents the budget closure: The turbulent fluctuations that are measured through the eddy correlation method are only part of the transfers that are involved in the ABL.

\section{Statistical Analysis}

The statistical analysis consists of representing normalised vertical profiles for each turbulent parameter to gather the data of all the flights of a measurement campaign. Our aim is to check whether the TRAC 98 data fit the statistical scaling usually used for the convective ABL and to detect a possible influence of coherent structures on these statistics. We used the convective scales defined by Deardorff (1972):

$$
\begin{aligned}
& \text { - length scale }(\mathrm{m}): Z_{i}, \\
& \text { - velocity scale }\left(\mathrm{m} \mathrm{s}^{-1}\right): w^{*}=\left[g Z_{i}\left(\overline{w^{\prime} \theta^{\prime}}\right)_{s} / \bar{T}\right]^{1 / 3}, \\
& \text { - temperature scale }(\mathrm{K}): \theta^{*}=\left(\overline{w^{\prime} \theta^{\prime}}\right)_{s} / w^{*}, \\
& \text { - humidity scale }\left(\mathrm{kg} \mathrm{kg}^{-1}\right): q^{*}=\left(\overline{w^{\prime} q^{\prime}}\right)_{s} / w^{*},
\end{aligned}
$$

where $g$ is the gravitational acceleration, $\theta$ the potential temperature, $w$ the vertical velocity, $q$ the mixing ratio and $\bar{T}$ a reference temperature of the ABL. The ' $s$ ' subscript corresponds to the covariance surface value. 

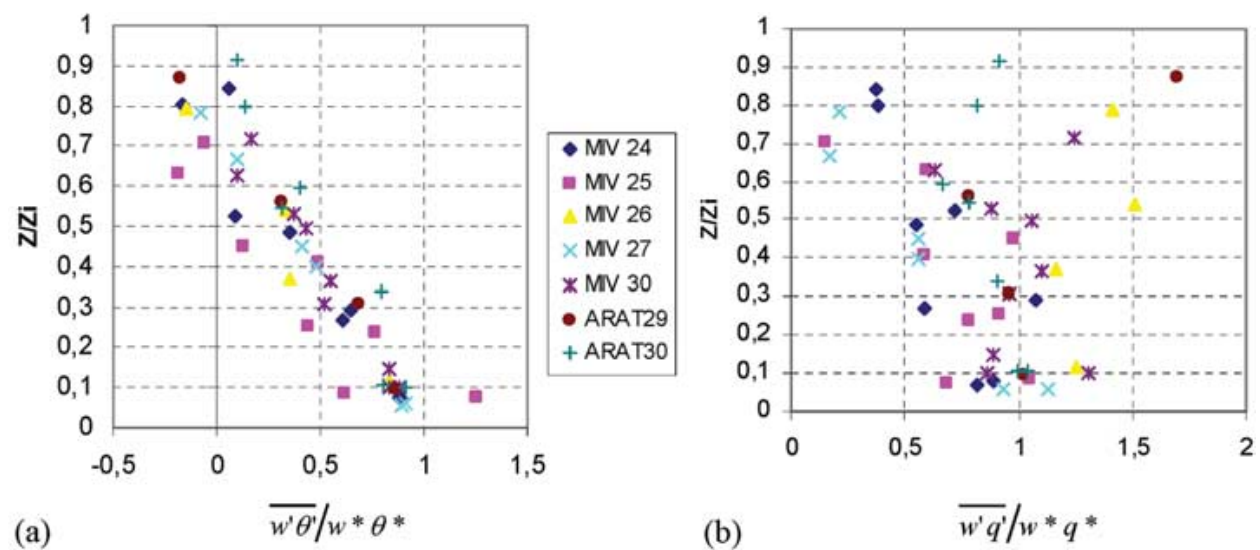

Figure 8. Vertical profiles of the normalized sensible (a) and latent (b) heat fluxes deduced from the data collected by the aircraft during seven flights of the TRAC98 experiment. Each of them is represented by a different symbol. The altitude is normalized by $Z_{i}$, the height of the ABL. Each experimental value is representative of an horizontal leg.

\subsection{Sensible (H) And latent heat (LE) Fluxes}

Vertical profiles for both heat fluxes are shown in Figure 8. The shape of the mean vertical profile obtained for $\mathrm{H}$ is consistent with those presented in the literature [Wyngaard et al. (1978) for the AMTEX flux under marine conditions with broken stratocumuli; Greenhut and Khalsa (1987) over the central Pacific Ocean; Nicholls and LeMone (1980) during the GARP Atlantic Tropical experiment GATE under clear or cumulus convection conditions; see Garratt (1992), Nieuwstadt and Duynkerke (1996) for a review on the convective ABL]. In our case, the most negative values are measured at the $0.9 Z_{i}$ level and represent $-20 \%$ of surface values on average, which is a generally accepted value for convectively driven, cloud-free boundary layers (Stull, 1988 and previous authors).

On the other hand, the weak scattering of the data collected during TRAC98 has to be underlined when compared to other literature results where relative variations can reach $20 \%$ (Druilhet et al., 1983) and 50\% (Lambert et al., 1999) at $0.1 Z_{i}$ or $50 \%$ in the whole ABL (Nicholls and LeMone, 1980). By contrast it is $12 \%$ during TRAC98 at $0.1 Z_{i}$ and less than $20 \%$ above. Wyngaard et al. (1978) and Greenhut and Khalsa (1987) also show weakly scattered results.

For the latent heat flux, the vertical profiles show different shapes according to the flights. For MIV24, MIV25, MIV27 and ARAT30 flights, the LE values decrease with altitude, whereas for MIV26, MIV30 and ARAT29 flights, they remain almost constant. These differences are explained by the relative importance of the evaporative flux at the surface and the entrainment flux at $Z_{i}$. Consequently, the LE vertical profiles shown on Figure $8 \mathrm{~b}$ give evidence of the variability of the entrainment phenomenon during the TRAC98 experiment. The scattering is then much more important than the one encountered for the sensible heat flux. This 
was also verified by Druilhet et al. (1983) and Lambert et al. (1999). Nicholls and LeMone (1980) pointed out that the sensible and latent heat fluxes of the GATE data, at the top of the mixed layer are strongly affected by the presence or absence of cumulus convection while the virtual heat flux remains unaffected. This would have probably required another scaling for $Z_{i}$ (sub-cloud layer scaling), by taking into account the depth of the cloud layer (cloud layer scaling) as proposed by Niewstadt and Duynkerke (1996). We did not need to do so, owing to the fact that our mean $Z_{c}$ was found to be very close to $Z_{i}$.

\subsection{VARIANCES AND CORRELATION COEFFICIENTS}

The vertical profiles of the normalized variance of the vertical velocity, the potential temperature and the mixing ratio, as well as those of the correlation coefficients are presented in Figure 9. In the literature, these variances are usually scaled using the mixed-layer scales presented above and also forced to match the local free convection conditions for continuity with the surface-layer scaling (Wyngaard and Izumi, 1971). This leads to power laws as proposed by Kaimal et al. (1976) for the Minnesota measurements, dependent on the normalized altitude $\mathrm{Z} / Z_{i}$ and valid in the first hundred metres of the ABL:

$$
\frac{\overline{X^{\prime 2}}}{X^{*}}=\alpha\left(Z / Z_{i}\right)^{\beta} \quad \text { (local free convection scaling) },
$$

where $\alpha$ is a constant value depending on the experimental estimations and on the studied parameter, with $\beta=2 / 3$ for $w$ and $-2 / 3$ for $\theta$ and $q$. The values of $\alpha$ were estimated for the three variances studied in this section. It is reported in Table IV and the corresponding power laws are represented on Figure 9. Values of this proportionality coefficient obtained for other experimental campaigns are also indicated in Table IV: They show that the coefficients obtained for TRAC98 are similar to those of the literature. However $\alpha$ for temperature variance (1.2) is somewhat smaller than those from literature (1.8 or 1.9). We tried to compare it to the coefficient proposed by Lenschow and Stephens (1980) who calculated the contribution of thermals to the total variance: They found a coefficient of 2.8 , which implies that our temperature fields would behave rather as downdrafts instead of updrafts. The height of the maximum exhibited on the vertical velocity variance occurs near $0.3-0.4 Z_{i}$ as found by most authors. This shows that the energy of the updrafts is maximum at this level. Higher in the ABL it is compensated by entrainment and pressure effects which lead to a deceleration (Lenschow and Stephens, 1980).

Sorbjan (1989) and Garratt (1992) made a review of the second-order moments over the whole ABL height. Our data, as with those reported by Sorbjan (1989), display much scatter for $Z>0.4 Z_{i}$. In fact, this variability can be reduced when using the concept of top-down and bottom-up processes. This concept, which includes the effect of convection (bottom-up) as well as entrainment (top-down), has 


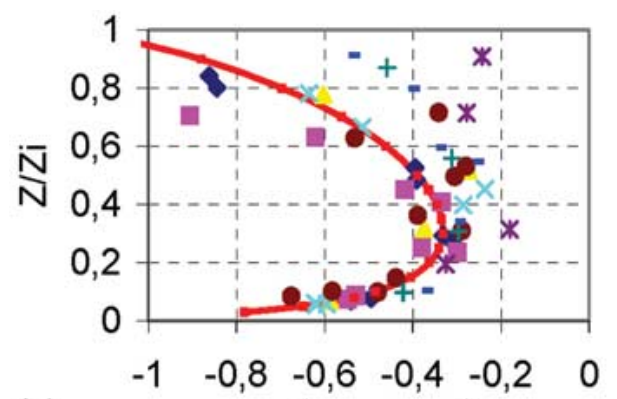

(a)

$$
\log \left(\overline{w^{\prime 2}} / w^{2}\right)
$$

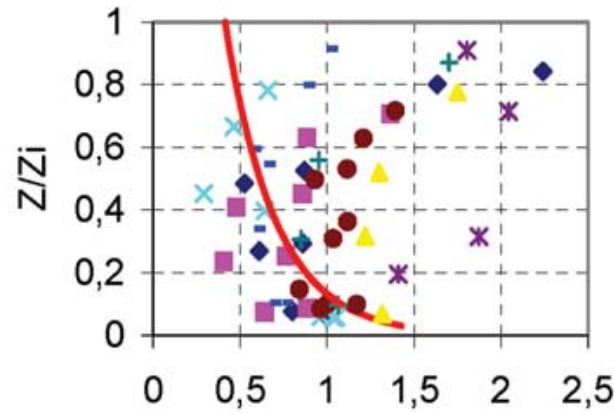

(c)

$$
\log \left(\overline{q^{\prime 2}} / q^{2}\right)
$$
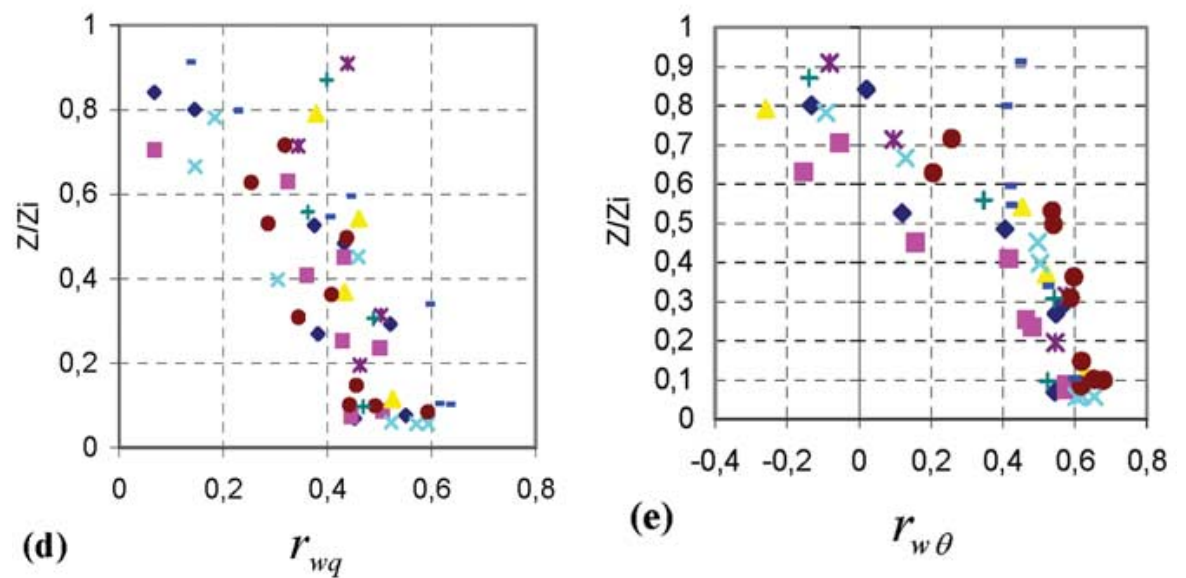

Figure 9. Same as in Figure 8 for the normalized variances (logarithmic scale) of the vertical velocity (a), potential temperature (b) and water vapour content (c) and (linear scale) for the correlation coefficients $r_{w q}$ (d) and $r_{w \theta}$ (e). Continuous curves, represented for the three variances, correspond to power laws proposed by various authors. (a) Lenschow et al. (1980), (b) red: Free convection scaling from Kaimal (1976) and mixed layer scaling from Lenschow et al. (1980); black: Same scaling fitted to TRAC98 with = 1.2; blue: Bottom-up scaling from Moeng and Wyngaard (1984), (c) free convection scaling from Kaimal (1976) and mixed layer scaling from Lenschow et al. (1980). 
TABLE IV

Proportionality coefficients of the free local convection exponential laws fitted to the normalized variances of the vertical velocity $(w)$, potential temperature $(\theta)$ and water vapour content $(q)$ measured during the TRAC98 experiment.

\begin{tabular}{llll}
\hline & $w$ & $\theta$ & $q$ \\
\hline TRAC 98 experiment & 1.6 & 1.2 & 2.59 \\
\hline Literature & Kaimal et al. (1976) & Kaimal et al. (1976) & Smedman and \\
& 1.8 & 1.8 & Högström (1973) \\
& Druilhet et al. (1983) & Druilhet et al. (1983) & 2.59 \\
& 2.1 & 1.9 & \\
& & Lenschow and & \\
& & Stephens (1983) & \\
& & 2.8 &
\end{tabular}

developed considerably due to the new insight provided by large-eddy simulation results. Moeng and Wyngaard (1984) and Sorbjan (1989) give new scaling formulae that result from this concept with several examples, showing that the scatter at the mixed-layer top is considerably reduced. In fact, bottom-up motions are scaled by $Z / Z_{i}$, similarly to the mixed-layer scaling, while the top-down motions are scaled by $\left(1-Z / Z_{i}\right)$.

Lenschow et al. (1980) proposed for instance the following parameterization for the velocity variance, which appears to fit the TRAC 98 data (red line on Figure 9):

$$
\overline{w^{\prime 2}}=1.8\left(\frac{Z}{Z_{i}}\right)^{2 / 3}\left(1-0.8\left(\frac{Z}{Z_{i}}\right)\right)^{2} \text {. }
$$

For temperature and humidity, Lenschow et al (1980) retained the local free convection parameterization proposed in (14), that we use with $\alpha=1.2$ (black line on Figure 9) for temperature. We also tried to use the bottom-up parameterization proposed by Moeng and Wyngaard (1984) which can also fit our data up to $0.6 Z_{i}$ (blue line):

$$
\overline{\theta^{*}}=0.47\left(\frac{Z}{Z_{i}}\right)^{-5 / 4}
$$

However, the $-5 / 4$ power law is less understandable and probably less consistent with the $-2 / 3$ power law of local free convection.

Fewer experimental data concerning the second-order moment of humidity are presented in the literature. Due to different entrainment conditions, the results usually do not converge towards a standard profile: Some of them show a decrease 
with height (Coulman, 1978; Nicholls and Readings, 1979) whereas the results of the Deardorff model (1974a) indicate a positive slope within the whole ABL. The TRAC98 data also reflect this variability. To reduce the variability, some additional scaling parameters have been proposed (Sorbjan, 1989; Moeng and Wyngaard, 1984). There are the entrainment rates $R_{\theta}$ and $R_{q}$, which are the ratio of the entrainment flux to the surface fluxes $\mathrm{H}$ and LE, and $\Delta$, the depth of the interfacial layer between the mixed and inversion layers. We do not use this scaling here because it did not work. In spite of the varying $R_{\theta}$ (range: -0.57 to 0 ) and $R_{q}$ values (range: 0 to 1 ), the statistics were not large enough to reach any conclusions: in fact, very similar values of $R_{\theta}$ or $R_{q}$ could result in totally different profile variances.

The variances are linked to the correlation coefficients by the following relationships:

$$
\begin{aligned}
& \overline{w^{\prime} \theta^{\prime}}=r_{w \theta}\left(\overline{w^{\prime 2}} \overline{\theta^{\prime 2}}\right)^{1 / 2}, \\
& \overline{w^{\prime} q^{\prime}}=r_{w q}\left(\overline{w^{\prime 2}} \overline{q^{\prime 2}}\right)^{1 / 2} .
\end{aligned}
$$

Taking into account the fact that both heat fluxes display a linear profile, and that the power laws in the local free convection layer are opposite, between velocity and scalars, we come to a constant value of the correlation coefficients in the surface layer that is imposed by the flux profile and the $\alpha$ coefficients. With the variance power laws previously determined and combined in Equations (17), we obtain 0.6 and 0.55 , respectively for temperature and humidity surface correlation coefficients. Note that $r_{w \theta}=0.6$ is a usual value in convective boundary layers (Coulman, 1978; Druilhet et al., 1983) while $r_{w q}=0.55$ is a very large value (Druilhet et al., 1983; Grant, 1992). The variability in the profiles of both coefficients reflects the variability encountered in the flux or variance profiles. Mann and Lenschow (1994) propose a sophisticated expression of $r_{w \theta}$ by combining bottom-up and top-down functions from Moeng and Wyngaard (1984), parameterized vertical velocity variance from Lenschow et al. (1980) (Equation (15)) and assuming a linear decrease of the sensible heat flux. This yields vertical profiles of $r_{w \theta}$ close to the TRAC98 ones, at least up to $0.5 Z_{i}$. Mann and Lenschow (1994) profile parameterizations vary according to $R_{\theta}$. Although this parameterization accounts well for the variability in the upper part of the ABL, it failed again when applied to our data, as it had with the second-order moments.

\subsection{SKEWNESS}

The skewness of a variable $x$ is defined as:

$$
S_{X}=\frac{\overline{x^{\prime 3}}}{\overline{\left(x^{\prime 2}\right)^{3 / 2}} .}
$$

The vertical profiles of the three skewnesses studied in this section are presented in Figure 10. The same scale for the horizontal axis is used in order to compare 

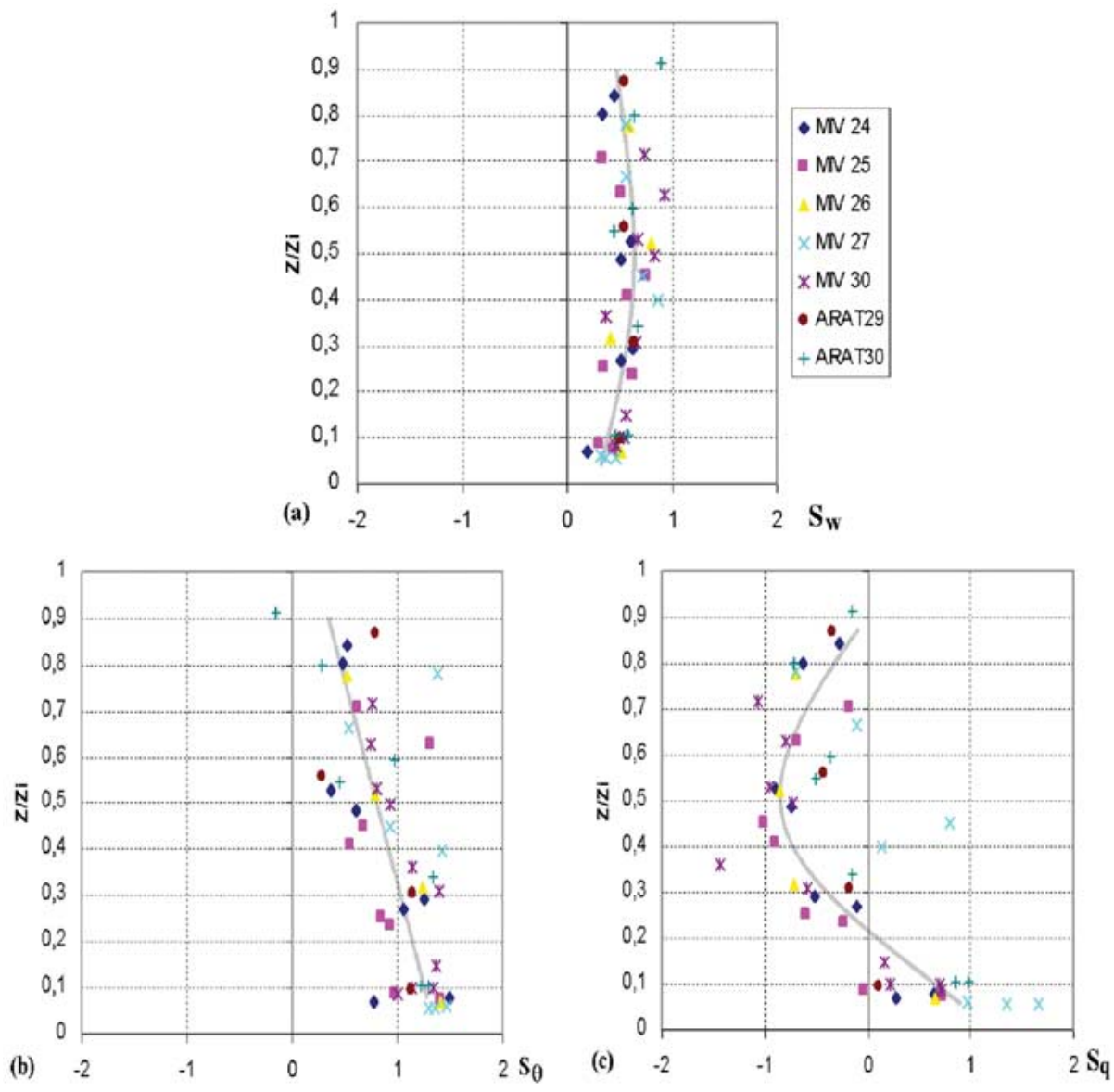

Figure 10. Same as in Figure 8 but for the skewness of the vertical velocity (a), potential temperature (b) and water vapour content (c).

the data scatter from one parameter to the other. Skewnesses vertical profiles and parameterizations are scarcer in the literature than other moments.

$S_{w}$ is positive throughout the whole boundary layer. Although the variations with height are not very important, there is a general shape of the vertical profile that characterizes the TRAC98 data: it corresponds to an increase of $S_{w}$ values up to about $0.5 Z_{i}$ and a decrease above. As noted by Mahrt and Paumier (1984), $S_{w}$ reaches a maximum at somewhat higher levels (around $0.5 Z_{i}$ ) than the level of maximum $w$ variance $\left(0.3-0.4 Z_{i}\right)$. Similar results were found by Coulman (1978), Lenschow et al. (1980) and Lambert et al. (1999). Sorbjan (1989) parameterizes these profiles using the entrainment rate $R$ and shows the results applied to the Lenschow et al. (1980) data from AMTEX. Once again, this parameterization 


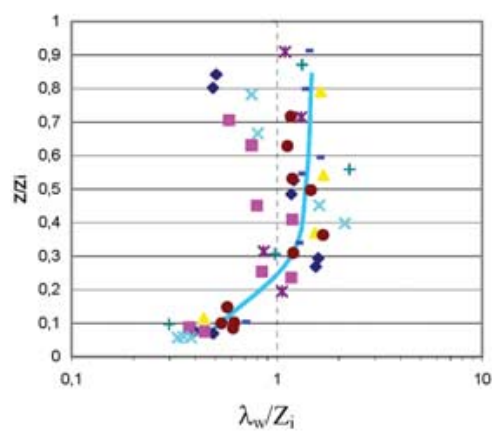

Figure 11. Same as in Figure 8 but for the length scale $\lambda_{w}$ normalized by $Z_{i}$. The continuous curve represents the law established by Kaimal et al. (1976) that is quoted in the text.

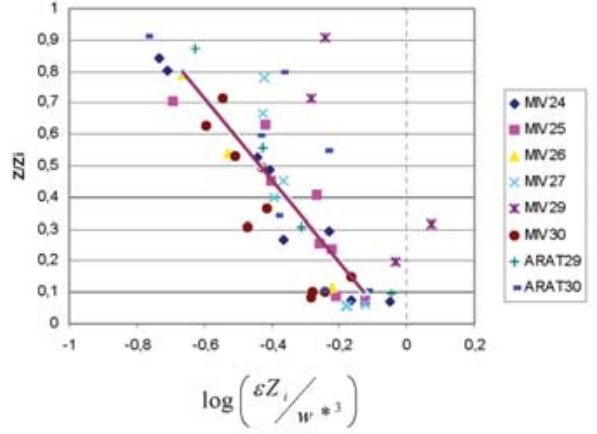

Figure 12. Same as in Figure 8 for the logarithm of the normalized dissipation rate of the turbulent kinetic energy. The mean vertical profile is also represented, and the corresponding equation is given in the text.

failed in the TRAC 98 case. TRAC98 $S_{w}$ profiles are not scattered and should not require any parameterization of that kind.

Nevertheless, other studies do not always agree with this profile shape in the upper part of the ABL. For example, Moeng and Wyngaard (1988) obtained, with a large-eddy simulation applied to a highly convective cloudless boundary layer, a $S_{w}$ profile that shows an increase from the surface and up to the ABL top. Réchou et al. (1995) obtained the same behaviour from data collected in the marine boundary layer of the Azores region. We will develop this idea later on by arguing that the skewness in vertical velocity is not systematically due to thermals (originated from the surface) but also to organizations that may have their source in the free troposphere. In the latter case, $S_{w}$ would increase near $Z_{i}$ due to the proximity to the source.

The $S_{\theta}$ values presented in Figure 10 are positive in the whole boundary layer and decrease from the surface up to $Z_{i}$. At the $0.1 Z_{i}$ level they are of the same order of magnitude as those presented in the literature, namely close to a mean value of 1.2 for the convective boundary layer (Coulman, 1978). In a marine boundary layer, the $S_{\theta}$ value at $0.1 Z_{i}$ is generally lower: for example, Lambert et al. (1999) obtained a mean value close to 0.6 . In other respects, the general shape of the $S_{\theta}$ profile obtained for TRAC98 is consistent with the one presented in the literature (Lambert et al., 1999). Nevertheless, Coulman (1978) showed a $S_{\theta}$ profile that tends towards negative values in the upper half of the mixed layer and explained that this behaviour is influenced by the entrainment of dry air. Finally, the $S_{\theta}$ values obtained for TRAC98 are more scattered than the $S_{w}$ ones.

Except for MIV27 flight, the $S_{q}$ vertical profile is the following: from the surface and up to $0.5 Z_{i}$, its values decrease to a negative minimum, and above $S_{q}$ increases 
to reach a value close to zero at the ABL top. The $S_{q}$ values are negative from the $0.2-0.3 Z_{i}$ level up to the top of the ABL except for the MIV27 flight for which the sign change occurs well above $0.3 Z_{i}$. At $0.1 Z_{i}$, the variation range of $S_{q}$ is large compared to $S_{w}$ and $S_{\theta}$. In fact, at this level, the $S_{q}$ values measured during the TRAC98 campaign vary between 0 and 1.5 whereas the values are within 0.2 and 0.5 for $S_{w}$, and within 0.75 and 1.5 for $S_{\theta}$.

In the literature, there are few data for humidity skewness. However, the analyzed profiles show the following common characteristics: Positive values of $S_{q}$ near the surface $\left(0.1 Z_{i}\right.$ level), and a decrease of $S_{q}$ above, leading to negative values of this parameter. The height at which the humidity skewness becomes negative differs from one experiment to the other. Coulman (1978) obtained $S_{q}$ profiles for which the value becomes negative from the $0.3 Z_{i}$ level as for the TRAC98 campaign. It was the same for the marine boundary layer studied by Réchou et al. (1995) in spite of an important scattering of the data from the $0.2 Z_{i}$ level. Over the same oceanic region, Lambert et al. (1999) showed for the SEMAPHORE experiment that the humidity skewness reached slightly negative values from the $0.6 Z_{i}$ level and vanished at the mixing layer top as in the TRAC98 experiment. This difference in the behaviour of $S_{q}$ can be explained by the entrainment process since the behaviour of $S_{q}$ in the boundary layer is tightly linked to this phenomenon. Many authors have noted this (Deardorff, 1974b; Coulman, 1978; Lambert et al., 1999; Attié et al., 1999), but no parameterization has been proposed yet. The dry air parcels, which are entrained through the boundary-layer top and which are stretched in narrow streamers when moving down through the boundary layer (Deardorff, 1974b), form a source of asymmetry for the relative humidity parameter. Strong entrainment ensures negative values for $S_{q}$, even in the lowest levels within the ABL (Deardorff, 1974b; Attié, 1999).

\subsection{WAVELENGTH ASSOCIATED WITH THE SPECTRAL PEAK OF THE VERTICAL VELOCITY, $\lambda_{w}$}

For TRAC98 data, the value of this parameter was determined by fitting the $w$ spectrum with the following law:

$$
n S(n)=\frac{a \frac{n}{n_{o}}}{1+a\left(\frac{n}{n_{o}}\right)^{5 / 3}},
$$

where $a$ and $n_{o}$ are constants whose values are adapted for each spectrum. $n$ is the frequency.

It has to be kept in mind that the $\lambda_{w}$ values can be affected by the occurrence of large wavelengths associated with coherent structures. Organizations like rolls or convective cells bring a low frequency contribution to the spectrum, which can result in a shift of the theoretical curve towards low frequencies, and then in an increase of the $\lambda_{w}$ value. 
Figure 11 presents, for each flight, the vertical profile of $\lambda_{w}$ normalized by the boundary-layer height $Z_{i}$. The relationship established by Kaimal et al. (1976) is also represented:

$$
\lambda_{w}=1.5 Z_{i}\left(1-\exp \left(-5 Z / Z_{i}\right)\right),
$$

for $0.1 Z_{i}<Z<Z_{i}$.

The TRAC98 experimental data are well represented by this law in the lower half of the boundary layer, but not in the upper part. For all the profiles, the $\lambda_{w}$ value normalized by $Z_{i}$ increases up to $0.3-0.4 Z_{i}$, also the level of the largest $w$ variance. At this height, it reaches a maximum value close to 1.5 on average: This means that the eddy size is greater than the boundary-layer thickness. In the upper half of the ABL, the data are more scattered: for some flights (MIV26 and ARAT30), the value of $\lambda_{w} / Z_{i}$ shows a tendency to keep constant, whereas for the others this value decreases. Caughey and Palmer (1979) also found a decrease in $\lambda_{w}$ close to the ABL top, which could reach 10 to $20 \%$ of its maximum value (maximum value was estimated $1.6 Z_{i}$ at $Z / Z_{i} \approx 0.6$, i.e., higher than the level of the maximum in TRAC98).

\subsection{TURBULENT KINETIC ENERGY DISSIPATION RATE, $\varepsilon$}

For the TRAC98 experiment, the turbulent kinetic energy dissipation rate is obtained by fitting the $-5 / 3$ law to the vertical velocity spectrum in the 1 to $10 \mathrm{~Hz}$ frequency range. For each flight, the normalized profile of $\varepsilon$ is presented in Figure 12. The mean profile of this parameter can be approximated for TRAC 98 by the following exponential law:

$$
\varepsilon /\left(w^{* 3} Z_{i}\right)=0.7 \exp \left(-Z /\left(0.9 Z_{i}\right)\right)
$$

for $0<Z / Z_{i}<0.8$.

Nevertheless, the experimental data are relatively scattered. Druilhet et al. (1983) have described the behaviour of $\varepsilon$ with a similar exponential law but with different coefficients. They found 1.26 for the proportionality coefficient and 0.8 for the exponential coefficient. Lenschow et al. (1980) as well as Guillemet et al. (1983) also indicate a slight decrease of the scaled dissipation rate with height, similar to that of TRAC98. In contrast, Caughey and Palmer (1979) have shown from Aschurch and Minnesota data that the normalized value of $\varepsilon$ is almost constant through the boundary-layer thickness. According to them, this behaviour of $\varepsilon$ is very close to what is observed in numerical and laboratory studies (Deardorff, 1974b; Willis and Deardorff, 1974). Even if it is not within the scope of our study, it is important to note that the sharp decrease of the dissipation rate at the top of the $\mathrm{ABL}$ is often used by modellers to detect the mixing-height. The algorithm used to detect this transition may not be the same, in the case of a constant or decreasing vertical profile. 
The statistical approach presented in this section shows that the vertical profile shapes for turbulent parameters measured during TRAC98 are similar to the ones presented in the literature, with very weak scattering, except for the turbulent parameters relative to humidity. This could have been linked:

- First to the decrease of the moments' accuracy near $Z_{i}$ due to the enhancement of heterogeneity (see the errors in Table I and especially the random error).

- Secondly to the varying entrainment conditions, but the scaling involving the entrainment rate failed and we will not keep this argument.

So, in spite of the rather classical behaviour of the convective ABL over the Beauce plain, these details supported the idea that there could be possibilities to detect the coherent structures we had observed by eye. That is what we are going to show in the following.

\section{Diagnosis of an Anisotropy Feature of the ABL}

Coherent structures can appear in the form of cells, or of horizontal rolls. The latter can be visualised by so-called cloud streets and are characterised by a wavelength that represents the distance between two consecutive updraft parts of the roll circulation, and by their orientation. Because of the existence of this preferred direction, this organization mode presents a feature of horizontal anisotropy.

On the other hand, it is known that the vertical transport associated with the rolls causes horizontal variability of heat and moisture. For instance, LeMone and Pennell (1976), by studying rolls in clear air, observed a temperature decrease of approximately $0.1 \mathrm{~K}$ and a vapour density increase of $0.5 \times 10^{-3} \mathrm{~kg} \mathrm{~m}^{-3}$ within the roll updrafts. In a similar study of clear air rolls, Reinking et al. (1981) noted increases of $0.5 \mathrm{~K}$ for the potential temperature and decreases of $3.5 \times 10^{-3} \mathrm{~kg} \mathrm{~m}^{-3}$ for the vapour density within the roll downdraft region at $0.67 Z_{i}$. More recently, Weckwerth et al. (1996) obtained potential temperature variations of about $0.5 \mathrm{~K}$ and water vapour mixing ratio variations of 1.5 to $2.5 \times 10^{-3} \mathrm{~kg} \mathrm{~m}^{-3}$ within the convective boundary layer and they showed that this variability is likely due to horizontal convective rolls. Brümmer (1999) classified the various cold air outbreak situations he encountered into roll cases, cell cases and a mix of both. He later studied the specific contribution of each class to the dynamic and thermodynamic properties of the ABL. The variability due to rolls or cells was observed from experimental data but also with numerical model simulations (Moeng and Sullivan, 1994). In a numerical study based on the TRAC93 data, Lohou et al. (2000) made 2D autocorrelation and 2D crosscorrelation analyses, using LES, to highlight the anisotropy of coherent structures. They showed that the anisotropy characterizing the coherent structures $(\approx 3 \mathrm{~km})$ was also found in the turbulence range (a few hundreds of metres). They concluded that the impact of coherent structures could be detected in the whole frequency range and that a 3D analysis was necessary to take account of the anisotropy. 
TABLE V

Results of the anisotropy analysis performed for six parameter values measured during five flights indicated in the first column. The six parameters given in the first lines are the filtering loss associated to sensible $(\mathrm{H})$ and latent (LE) heat fluxes, the wavelength associated to the spectral peak of the vertical velocity $\left(\lambda_{w}\right)$ and the skewness of the vertical velocity $\left(S_{w}\right)$, potential temperature $\left(S_{\theta}\right)$ and water vapour content $\left(S_{q}\right)$. Information is given only for cases for which anisotropy was diagnosed. This information is the direction associated with the strongest values of the considered parameter. The directions $\mathrm{N}-\mathrm{S}$ and $\mathrm{E}-\mathrm{W}$ are the north-south and east-west directions respectively. The symbols $\perp$ and // are for crosswind and alongwind.

\begin{tabular}{|c|c|c|c|c|c|c|}
\hline \multirow[b]{2}{*}{ Flight } & \multicolumn{2}{|c|}{ Filtering loss } & \multirow[b]{2}{*}{$\lambda_{w}$} & \multirow[b]{2}{*}{$S_{w}$} & \multirow[b]{2}{*}{$S_{\theta}$} & \multirow[b]{2}{*}{$S_{q}$} \\
\hline & $\mathrm{H}$ & LE & & & & \\
\hline MIV24 & & // & & $\perp$ & & \\
\hline MIV25 & & & $\mathrm{N}-\mathrm{S}$ & & & \\
\hline MIV27 & $\mathrm{N}-\mathrm{S}$ & & $\mathrm{N}-\mathrm{S}$ & $\mathrm{N}-\mathrm{S}$ & & E-W \\
\hline ARAT30 & $\perp$ & $\perp$ & $\perp$ & $\perp$ & $\perp$ & \\
\hline MIV30 & & // & $/ /$ & & & \\
\hline
\end{tabular}

The data collected during TRAC98 are well adapted for the anisotropy study because the aircraft have documented the ABL in two perpendicular directions at different levels. It enabled representation of the vertical profiles of airborne parameters according to the sampling direction for all the flights during which two vertical planes, at least, were documented (MIV24, MIV25, MIV27, MIV30 and ARAT30 flights).

We selected six relevant parameters: The filtering loss for the latent and sensible heat fluxes, the wavelength associated with the peak of the vertical velocity spectrum and the skewness of vertical velocity, potential temperature and mixing ratio. The vertical profiles of these six relevant parameters are presented as an example for ARAT30 flight in Figure 13. The results are reported in Table V along with those from other flights. Only cases for which an anisotropy feature was diagnosed are indicated in this table: The direction associated with the highest values is pointed out.

The objective is to determine, for each flight, whether the ABL is characterized by a preferred direction from the results reported in Table V. We first analysed the behaviour of $\mathrm{FL}(\mathrm{H}), \mathrm{FL}(\mathrm{LE})$ and $\lambda_{w}$. These three parameters are linked. In fact, the filtering loss values reflect the contribution of motions with length scale greater than $5 \mathrm{~km}$ : if these motions are more important in the north-south direction, then it 

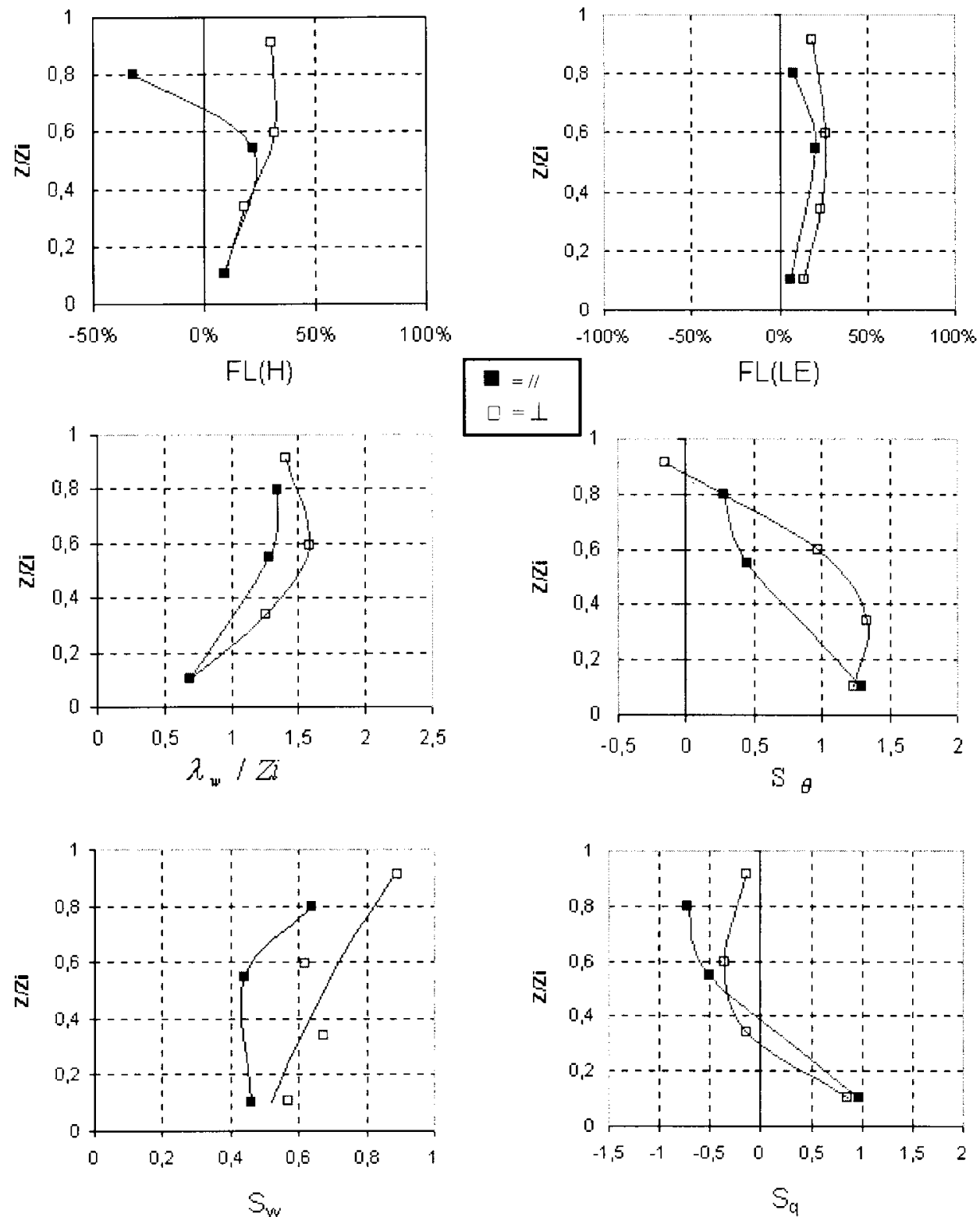

Figure 13. Results of the anisotropy analysis for the ARAT30 flight. The vertical profiles of six parameters are represented according to the sampling direction: The symbols $\mathbf{\square}$ and $\square$ correspond to measurements in planes oriented alongwind and crosswind respectively. The six parameters are: the filtering loss associated with the sensible and latent heat fluxes (noted FL(H) and FL(LE)), the wavelength $\lambda_{w}$, and the skewness of the vertical velocity $\left(S_{w}\right)$, mixing ratio $\left(S_{q}\right)$ and potential temperature $\left(S_{\theta}\right)$. 
is likely that the $\lambda_{w}$ value is greater in this direction as well, due to the shift of the spectral peak towards low frequencies.

For instance, for the ARAT30 flight, the results in Figure 13 and Table V concerning $\mathrm{FL}(\mathrm{H}), \mathrm{FL}(\mathrm{LE})$ and $\lambda_{w}$ parameters are consistent with this reasoning: The north-south crosswind plane presents larger filtering loss and larger characteristic length scales, which suggests coherent structures with a preferred direction oriented crosswind. This is not usual since several authors present structures that are aligned with the wind (Nicholls and LeMone, 1980: Cumulus clouds; LeMone, 1990: Roll vortices) or elongated in the wind direction (Lenschow and Stankov, 1986; Lambert and Durand, 1999). However Lohou et al. (1998b) showed that the preferred direction could also been aligned with the shear vector: we checked this hypothesis using the shear information that is indicated in Table II. The direction of the wind shear for ARAT $30\left(126^{\circ}-306^{\circ}\right)$ is different from that of the preferred direction $\left(360^{\circ}\right)$ so this hypothesis is not valid. In contrast, we will argue in the following that the forcing from gravity waves at the top of the ABL may be the source of the encountered organization.

Figure 13 shows that $S_{w}$ and $S_{\theta}$ also appeared to be the largest in this direction. In contrast, $S_{q}$ is not clear. This preferred direction is represented in Figure 14 for the ARAT30 case as well as for the other concluding results of Table V. Only three of the five flights led to a conclusion of a preferred direction. $S_{w}$ is still the largest in the preferred direction in the case of the MIV27 flight. That is a point that has to be cleared. Figure 15 represents some $S_{w}$ functions for ARAT30, with 2 pairs of crossing legs at $0.6 Z_{i}$ and $0.9 Z_{i}$. On the left part, updrafts are less numerous but stronger and better organized at $0.9 Z_{i}$ (top) than in the middle of the $A B L$ (bottom). $S_{w}$ is the largest at $0.9 Z_{i}$. If we now compare the left part (preferred direction) to the right part (perpendicular to preferred direction), we can notice that updrafts are numerous and far less extended (spatially) on the right $(\perp)$ than on the left (preferred direction) which leads to less skewed functions. So, $S_{w}$ would be the largest when the aircraft flies through large and well organized updrafts, associated with large areas of downdrafts: the probability to meet these conditions is the highest when the structures are cut along their longest dimension. This is consistent with the results of the analysis performed by LeMone (1990) concerning $S_{w}$. She observed (but did not explain) that organized structures induce a decrease of $S_{w}$ in the direction perpendicular to the structures preferred axis. Nevertheless, we will make the same hypothesis for $S_{\theta}$ skewness according to the behaviour of this parameter for the ARAT30 flight.

The profiles of $S_{w}$ were also examined for MIV27. The only difference with the ARAT30 case is that for MIV27, $S_{w}$ displays a more classical profile with skewness decreasing at high levels (see Figure 10a for reference). This difference comes probably from the fact that organization is created at the surface for MIV27 while it is imposed by mesoscale forcing at the ABL top in the second situation. In the first case, updrafts have lost part of their energy at $0.9 Z_{i}$ whereas it is the 


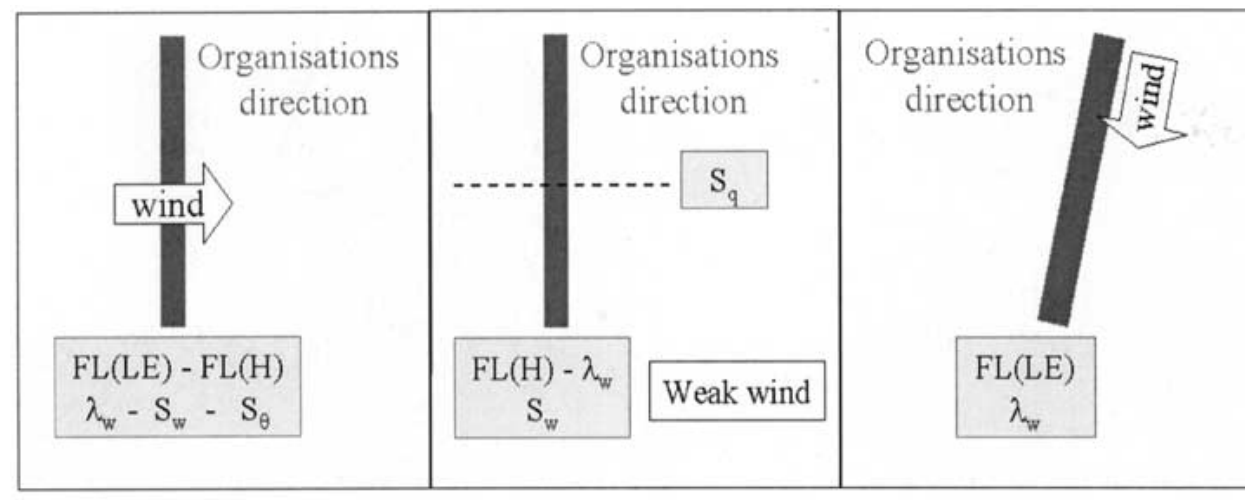

ARAT30 flight

MIV27 flight

MIV30 flight

Figure 14. Organization scheme deduced from the anisotropy analysis for three flights: ARAT30, MIV27 and MIV30. The preferred direction is indicated by a thick line. The wind direction, when it is defined, is reported as well as the results of the anisotropy diagnosis. The parameters are given in the direction in which their highest values have been measured.

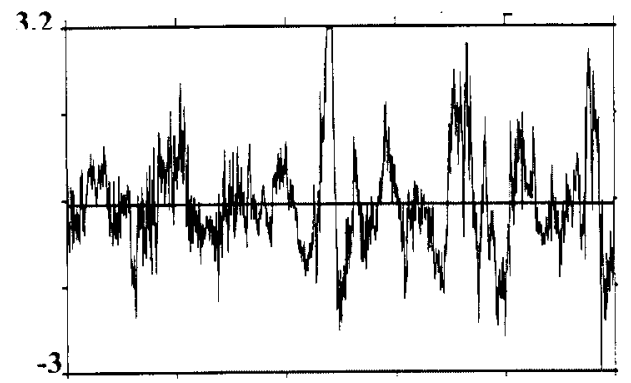

$\mathrm{Z}=0.9 Z_{\mathrm{i}} \quad \mathrm{S}_{\mathrm{w}}=\mathbf{0 . 8 8}$

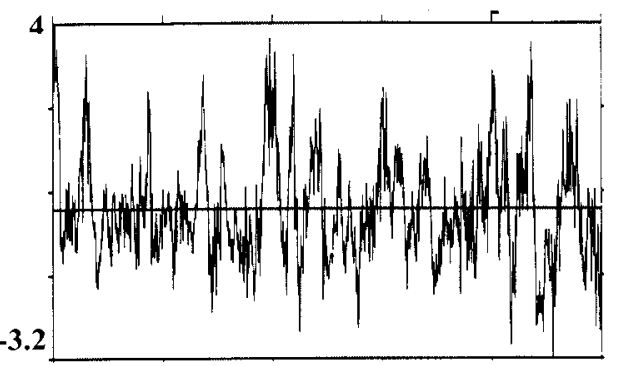

$\mathrm{Z}=0.6 \mathrm{Z}_{\mathrm{i}} \quad \mathrm{S}_{\mathrm{w}}=0.61$

$/ /$ to preferred direction (crosswind)

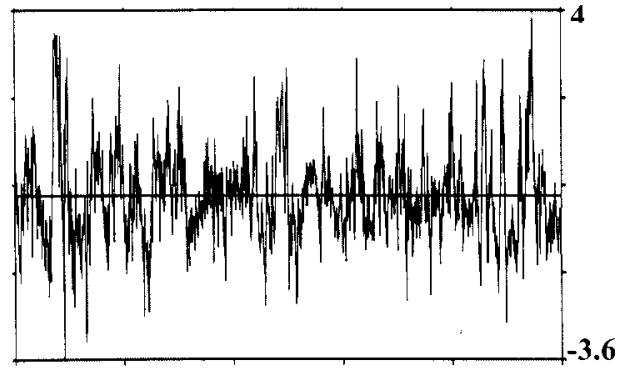

$\mathrm{Z}=0.9 Z_{\mathrm{i}} \quad \mathrm{S}_{\mathrm{w}}=\mathbf{0 . 6 2}$

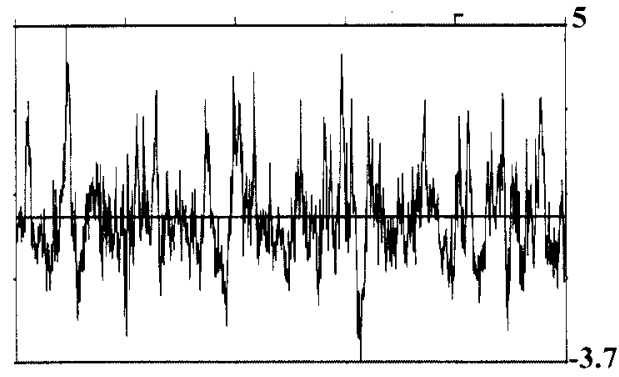

$Z=0.6 Z_{i} \quad S_{w}=0.42$

$\perp$ to preferred direction (alongwind)

Figure 15. Vertical velocity skewness functions for ARAT 30 along (left) and across (right) the preferred direction of the coherent structures at $0.6 Z_{i}$ (bottom) and $0.9 Z_{i}$ (top). The leg length is $32 \mathrm{~km}$ on average. 
largest at this level when the source of skewness is coming from the top. We cannot conclude the same for $S_{q}$ which was identified for one flight only (MIV30).

The anisotropy was investigated for other parameters such as fluxes, secondorder moments, turbulence rates (ratio of second-order moments to the mean wind), dissipation rates for turbulent kinetic energy and half variance of temperature and humidity, integral scales as defined by Lenschow and Stankov (1986) and used by Lohou et al. (2000), to highlight the anisotropy in the turbulent range. Some of these parameters were not good indicators of anisotropy (fluxes, second-order moments, turbulence rates). Others, like parameters of the high frequency spectrum range simply replicated the behaviour of their homologues in the whole frequency range: $\varepsilon$ for instance was like $\overline{w^{\prime 2}} ; l_{w}$, the integral scale for $w$, like $\lambda_{w}$ etc. So an anisotropy appeared for $l_{w}$, as it had for $\lambda_{w}$ but no additional information was provided, except the confirmation of Lohou et al. (2000) that the influence of the coherent structures is widespread over the whole energy spectrum range.

The possibility of determining the preferred direction of the organization provided that the parameters were chosen with consistency has been a fundamental point of our study. We will use data for the case of ARAT30 flight in order to reinforce the previous results.

\section{ARAT30 Flight Analysis}

The aim of this section is to complete the horizontal anisotropy analysis by using methods that allow us to characterize the variations along the legs. Until now, the statistical and the anisotropy character studies were based on mean values representing the whole leg and neglecting variations in the inner leg. In the following, we are going to study these variations using two distinct methods. The first approach consists in analysing the low-level cloud cover as the clouds are considered to be a good indicator of the ABL organization.

\subsection{Cloud COVER CHARACTERISTICS}

Two parameters measured by the aircraft can be used to obtain the cloud cover characteristics: the downward visible radiation (noted VISD) and the downward infrared radiation (noted IRD). The information they supply is not the same as shown as an artist's view in Figure 16. It indicates that the VISD signal depends on the aircraft position relative to the sun-cloud axis, i.e., the VISD parameter is a tracer of the cloud shadows. In contrast, the IRD signal values are directly linked to the cloud positions. So, Figure 16 underlines the fact that the clouds detected by the downward visible or infrared radiation may be slightly apart.

Due to the presence of high level clouds ( $\mathrm{Sc}$ ), the VISD radiation appeared to be more adapted for our analysis as it distinguishes more precisely the transitions between the areas with or without clouds. A statistical method was developed to 


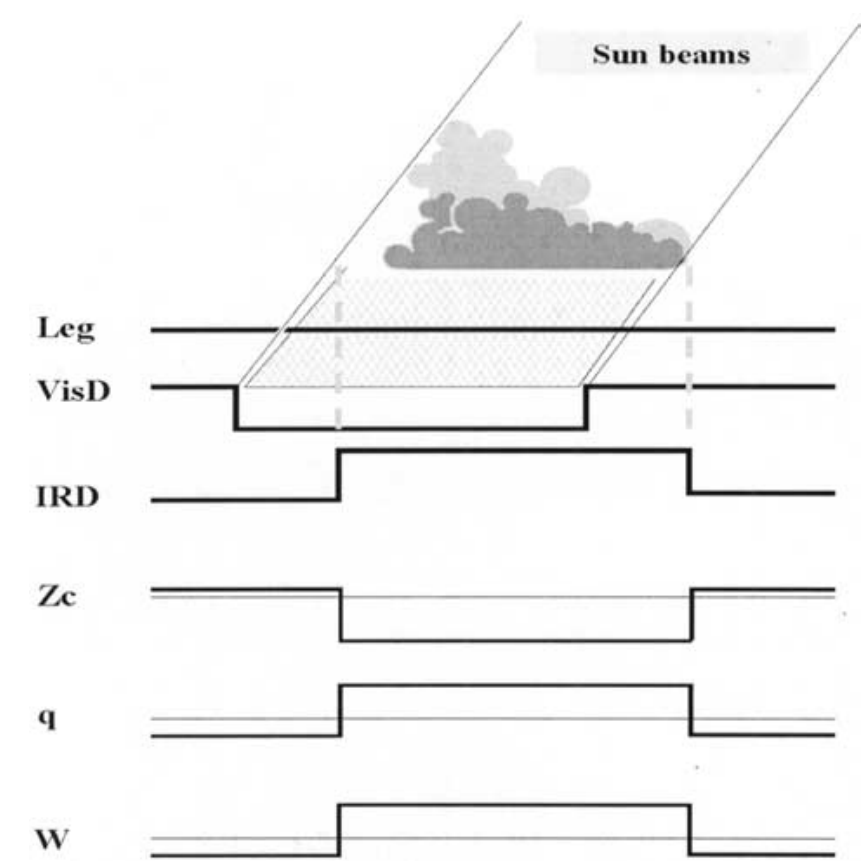

Figure 16. Composite view of radiative, thermodynamic and dynamic parameters measured by the aircraft under a cumulus: The horizontal line represents an horizontal flight leg; the shortwave downward (VISD) values are linked to the cloud shadow whereas the infrared downward (IRD) values are directly linked to the cloud. The other three parameters are the the lifting condensation level $\left(Z_{c}\right)$, the humidity mixing ratio $(q)$ and the vertical velocity $(w)$.

characterize ABL cumulus through three parameters: The percentage of the area covered by clouds, their mean size and corresponding standard deviation and their mean number over a horizontal distance of $100 \mathrm{~km}$. This method requires applying a high-pass filter to the VISD measurement series in order to remove the influence of high levels clouds. Then a threshold value was defined to eliminate the low amplitude fluctuations of the VISD filtered values that are not sufficiently representative of the low level clouds.

The results of this analysis are presented in Table VI. Two main conclusions can be inferred. First, the north-south flight path (crosswind) is more cloudy: The percentage of area covered by the clouds is $35 \%$ in the north-south direction and $28 \%$ in the perpendicular direction. Secondly, the clouds mean size values clearly indicate a larger horizontal extent in the north-south direction: this difference is close to a factor two. So, the statistical analysis reveals a directional anisotropy of the clouds. Considering that the updraft parts of the coherent structures are located under the clouds, this result is consistent with the results from previous sections where we argued that the updrafts were longest and most organised in the preferred direction. These properties are investigated further in the next section. 
TABLE VI

Results of the statistical analysis of the low-level cloud cover of the ARAT30 flight: Percentage of area covered by clouds, mean cloud size and the associated standard deviation, mean number of clouds over a horizontal distance of $100 \mathrm{~km}$. Symbols $\perp$ and // are for cross and along-preferred direction.

\begin{tabular}{lllll}
\hline LEG & $\begin{array}{l}\text { Orientation relative } \\
\text { to organization } \\
\text { preferred direction }\end{array}$ & $\begin{array}{l}\text { Size } \pm \text { standard } \\
\text { deviation } \\
(\mathrm{m})\end{array}$ & $\begin{array}{l}\text { Number of clouds/ } \\
100 \mathrm{~km}\end{array}$ \\
\hline 1 & $/ /$ & 29 & $770 \pm 480$ & 38 \\
2 & $/ /$ & 35 & $650 \pm 590$ & 53 \\
3 & $/ /$ & 40 & $720 \pm 640$ & 58 \\
4 & $/ /$ & 40 & $450 \pm 540$ & 89 \\
& & & & \\
6 & $\perp$ & 27 & $330 \pm 310$ & 83 \\
7 & $\perp$ & 28 & $350 \pm 430$ & 80 \\
8 & $\perp$ & 30 & $450 \pm 400$ & 68 \\
\hline
\end{tabular}

\subsection{CORRELATION STUdY}

This approach is based on four parameters: the radiative signal VISD previously presented, the lifting condensation level $Z_{c}$, the vertical velocity $w$ and the mixing ratio $q$. It consists of searching for the relationship between the four parameters through a correlation analysis which provides:

- The degree and sign of the correlation between two parameters;

- the diagnosis of an eventual periodicity which would indicate an organization.

We propose in Figure 16 a schematic view of the relative behaviour of the four components for a vertical updraft. The VISD radiative flux decreases due to the cloud shadow. The positive vertical velocity induces a local increase of the water vapour mixing ratio and therefore a decrease of the lifting condensation level. Furthermore, close to the ABL top the entrainment process tends to dry the air in the downdraft parts (Lenschow and Stephens, 1980). In contrast, temperature is not such a good indicator of upward and downward motions since the eddies that are brought down by entrainment from the upper warmer layers tend to warm the downdrafts that cannot be distinguished from the updrafts where the temperature is also in excess (Lenschow and Stephens, 1980).

The method consists, in a first step, of using band-pass filtering for each data series in order to consider wavelengths situated between $100 \mathrm{~m}$ and $10 \mathrm{~km}$ only. This processing aims at reducing the signals to a common frequency range which involves the frequencies characteristic of coherent structures. Correlation coefficients are calculated between pairs of the filtered functions and the representation 


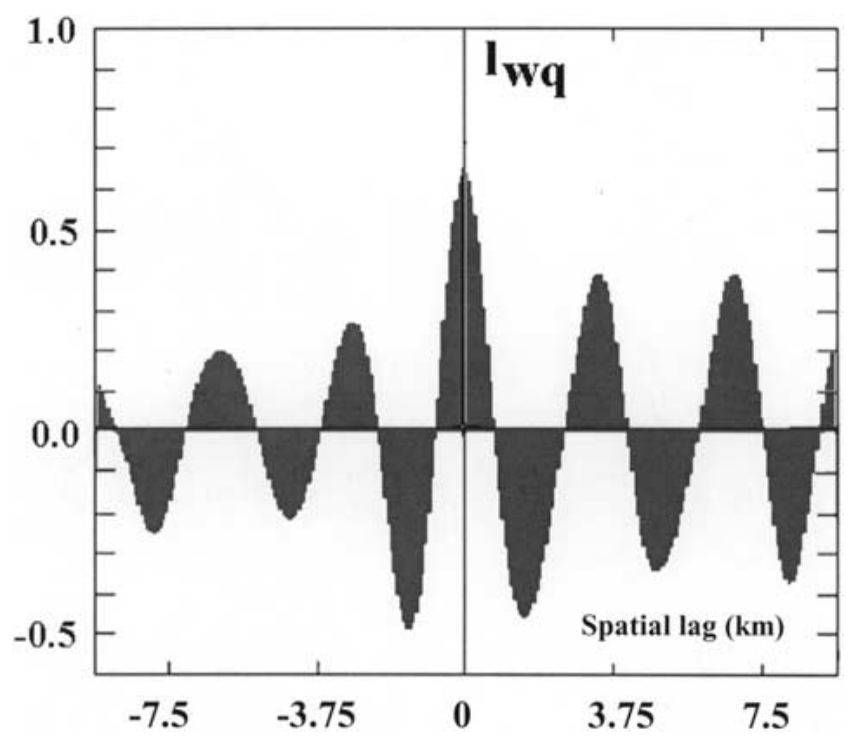

Figure 17. Example of an intercorrelation function between the vertical velocity and mixing ratio obtained along the leg performed crosswind at $0.35 Z_{i}$ during the ARAT30 flight. On the $\mathrm{x}$-axis, are reported different spatial lags between the two measurements series. The correlation coefficients are indicated on the $y$-axis. The intercorrelation function shows a periodic character and allows us to determine a length scale in relation with the periodicity: in this case, it is $3480 \mathrm{~m}$.

of the resulting correlation coefficients as a function of the temporal lag provides the intercorrelation function. An example is given in Figure 17 in the case of the vertical velocity and mixing ratio measured along the second leg of the ARAT30 flight $\left(Z=0.35 Z_{i}\right)$.

When the intercorrelation functions are periodic, length scales characterizing this periodicity are estimated. This feature indicates that the variations of the two analysed parameters measured along the leg considered show a periodicity that is common to the two signals and that can be linked to coherent structure occurrences.

Table VII gives for each leg indicated in the first column and for each of the six pairs of parameters the correlation coefficient value obtained for a null temporal lag between the two functions. Two remarks can be inferred from these results. First, the degree of correlation is often important in absolute value. For example, the fact that the correlation coefficient varies between 0.45 and 0.7 for the couple $(w, q)$ is significant. Secondly, the sign of the six correlation coefficients is coherent and confirms the scheme of the relative behaviour of the four parameters $Z_{c}$, VISD, $w$ and $q$ presented on Figure 16. The correlations including VISD at low level are not trustworthy since the cloud shadow is probably displaced.

The results of the correlation analysis in term of length scales are reported in Table VIII with a presentation similar to the one of the previous table. When the intercorrelation function was not periodic, no wavelength was estimated. The wavelength values obtained vary between 1640 and $4300 \mathrm{~m}$. They are undoubtedly 
TABLE VII

Values of the correlation coefficients determined for six pairs of parameters given in the first line of the table and for each leg performed within the ABL during the ARAT30 flight. $Z_{c}, w, q$ and VISD are the lifting condensation level height, vertical velocity, water vapour content and downward visible radiation respectively. Symbols $\perp$ and // are for across and along the preferred direction.

\begin{tabular}{lllllll}
\hline $\mathrm{LEG}$ & $\mathrm{R}\left(Z_{c}, w\right)$ & $\mathrm{R}\left(Z_{c}, q\right)$ & $\mathrm{R}\left(Z_{c}, \mathrm{VISD}\right)$ & $\mathrm{R}(w, q)$ & $\mathrm{R}(w, \mathrm{VISD})$ & $\mathrm{R}(q, \mathrm{VISD})$ \\
\hline $1(/ /)$ & -0.15 & -0.58 & & 0.69 & & \\
$2(/ /)$ & -0.23 & -0.82 & 0.14 & 0.6 & -0.09 & -0.16 \\
$3(/ /)$ & -0.26 & -0.85 & 0.08 & 0.64 & -0.15 & -0.08 \\
$4(/ /)$ & -0.4 & -0.95 & 0.28 & 0.45 & -0.19 & -0.4 \\
& & & & & & \\
$6(\perp)$ & -0.28 & -0.88 & 0.23 & 0.51 & -0.15 & -0.16 \\
$7(\perp)$ & -0.31 & -0.86 & 0.24 & 0.55 & -0.12 & -0.24 \\
$8(\perp)$ & -0.13 & -0.48 & & 0.7 & & \\
\hline
\end{tabular}

the sign of the occurrence of coherent structures within the boundary layer according to the range of the lengthscales associated with these physical phenomena (Etling and Brown, 1993; Atkinson and Wu Zang, 1996; Brümmer, 1999). On the other hand, the wavelengths values do not seem to depend on the sampling direction. For the particular ARAT30 flight, the final direction of the organizations is often perpendicular to the wind direction in the ABL. We said before it is not linked to the wind shear direction between the ABL and the free atmosphere. The perpendicularity suggests that the organizations are driven by gravity waves propagating above the ABL. This is supported by the comparison of the two independent length scales: the mean length scale obtained from the correlation function analysis which is $2.7 \mathrm{~km}$ on average and the Brunt-Väisälä wavelength of $3.6 \mathrm{~km}$ calculated in Section 2.3.

The last point to examine for the ARAT30 case is the relationship between the anisotropy and the flux underestimation pointed out in Section 2.4. It was only 33 $\mathrm{W} \mathrm{m}{ }^{-2}$ for the alongwind plane whereas it was $85 \mathrm{~W} \mathrm{~m}^{-2}$ in the coherent structures preferred direction. In the latter case, the hypothesis of horizontal homogeneity and Gaussian distribution required to calculate an eddy flux, were clearly not respected. We can add that the same conclusion can be drawn with MIV27 and MIV30, for which the preferred direction (north-south) showed the largest underestimation. However, these last two cases also show that crossing the coherent structures along their shortest dimension does not prevent flux underestimation, since $U$ remains very high whatever the sampling direction is.

To close this case study, we propose in Figure 18 an artist's view of the organizations detected by the aircraft for the ARAT30 flight, which can be deduced 
TABLE VIII

Same as in Table VII for the wavelength (in $\mathrm{m}$ ) deduced from the intercorrelation functions. Values are indicated only when the latter show a periodic character.

\begin{tabular}{lllllll}
\hline LEG & $\mathrm{R}\left(Z_{c}, w\right)$ & $\mathrm{R}\left(Z_{c}, q\right)$ & $\mathrm{R}\left(Z_{c}, \mathrm{VISD}\right)$ & $\mathrm{R}(w, q)$ & $\mathrm{R}(w, \mathrm{VISD})$ & $\mathrm{R}(q, \mathrm{VISD})$ \\
\hline $1(/ /)$ & $/$ & $/$ & $/$ & 4000 & $/$ & $/$ \\
$2(/ /)$ & $/$ & $/$ & 3420 & 3480 & 3500 & 3260 \\
$3(/ /)$ & 2210 & 2140 & $/$ & $/$ & 4300 & 2400 \\
$4(/ /)$ & $/$ & 1830 & 1640 & 2470 & $/$ & 1700 \\
& & & & & & \\
$6(\perp)$ & 2170 & 2130 & $/$ & $/$ & $/$ & 2150 \\
$7(\perp)$ & $/$ & $/$ & 3200 & 2470 & $/$ & $/$ \\
$8(\perp)$ & $/$ & $/$ & 2970 & 3260 & $/$ & $/$ \\
\hline
\end{tabular}

from the previous results. On the top figure (T), the wind is perpendicular to the figure plane while it is parallel on the bottom figure (B). Updrafts are supposed to be symmetrical in $\mathrm{T}$ and sheared by the wind in $\mathrm{B}$. These updrafts that are warmer than the environment at low $Z / Z_{i}$, tend to be colder than the environment near their top, due to the warm air entrained from the inversion layer (represented as vortices). The cloud cover which highlights the updrafts is aligned crosswind, with a larger spacing between clouds in the wind direction whereas the clouds are stretched in the other direction. In $\mathrm{B}$, the two different estimations of the ABL height are drawn with an opposite phase shift since $Z_{i}$ is the highest under the clouds while $Z_{c}$ is the lowest. The length scale appearing in the wind direction is probably forced by gravity waves coming from the low troposphere. Finally, if the aircraft cuts the field along the $Y$ direction (crosswind), it is likely to cross a few long and very energetic updrafts. The $w$ function is very skewed and the surface heat flux is not well estimated. This situation is less dramatic in the case of a flight in the perpendicular direction (alongwind or $X$ axis), where the functions remain nevertherless rather skewed.

The consistency of these results shows that despite the one-dimensional aircraft sampling and of the different ways to 'cut' the coherent structures, we managed to identify precisely the organization of the ABL from airborne data.

\section{Conclusion}

The long term scientific goal of the TRAC program is to quantify the respective contributions of small scale turbulence and coherent structures in vertical exchanges within the ABL. Several means were deployed during the experimental 

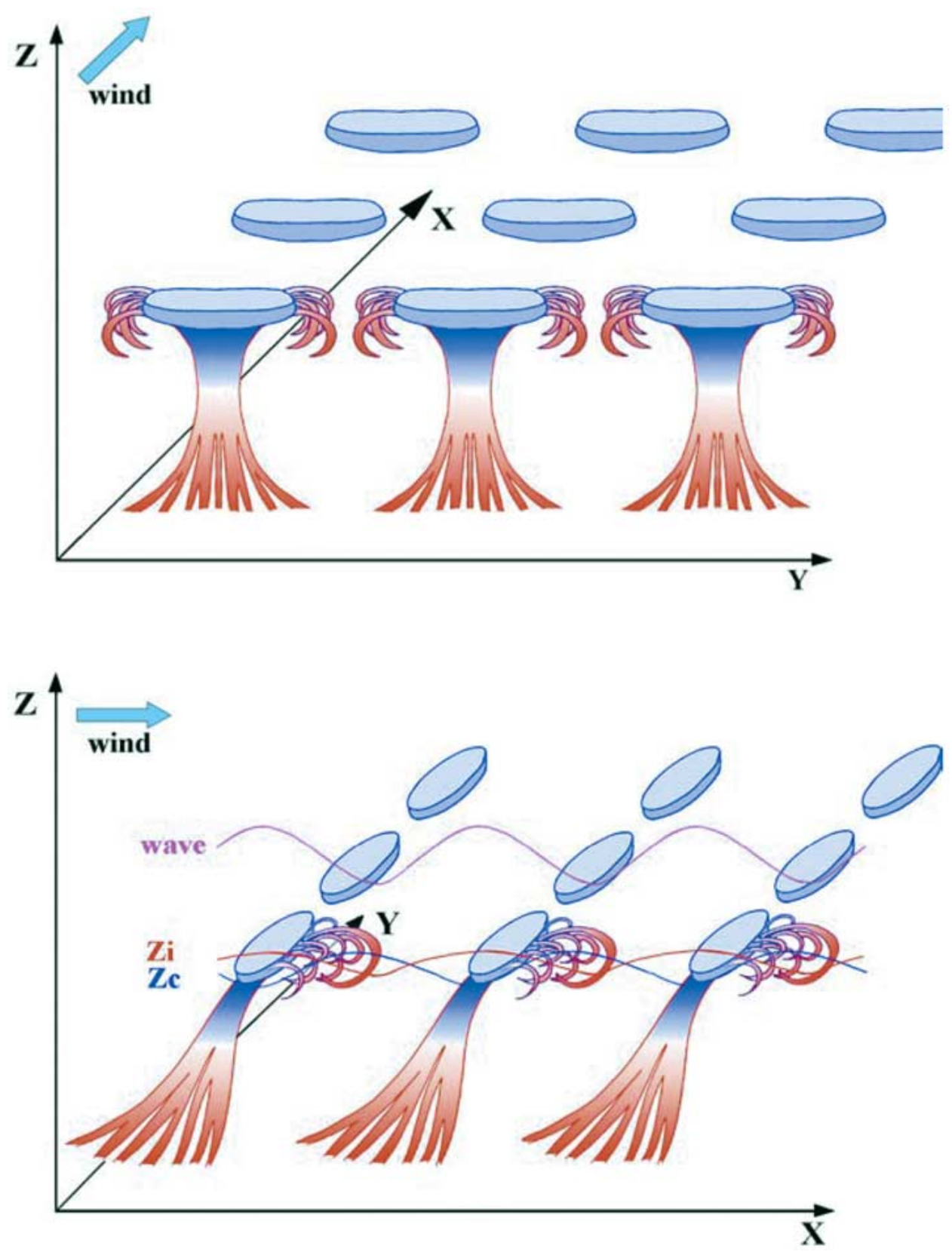

Figure 18. An artist's view of the organizations detected by the aircraft for the ARAT30 flight. See text for details. 
campaign TRAC98 to reach this objective. The work presented in this paper consisted in using airborne results to present different approaches in order to point out the occurrence of coherent structures within the ABL and to give information on the organization mode. A classical analysis was performed through a statistical approach. This representation, using classical parameterizations of the convective mixed layer underlined the homogeneity of the ABL over the Beauce plain up to $0.5-0.6 Z_{i}$. Higher in the ABL, parameterizations using the entrainment rate to reduce the variability failed. Other methods were therefore investigated to explain this variability.

The first consisted of representing vertical profiles of turbulence parameters, for each flight, taking into account the sampling direction. This study was based on the hypothesis that the organised structures do not have the same influence in all directions on the dynamic and thermodynamic parameters measured within the ABL. In this way, six parameters have been analysed: The filtering loss associated with the latent and sensible heat fluxes, the wavelength associated with the vertical velocity spectral peak, and the skewness of the vertical velocity, potential temperature and mixing ratio. The anisotropy was studied for five flights during which two perpendicular vertical planes, at least, have been documented by the aircraft. The results obtained allowed us to determine an organizational direction for three flights: MIV27, MIV30 and ARAT30. These three cases correspond to three different configurations: For one of them, the wind measured within the ABL is weak (MIV27), for a second one, the ABL wind has a well defined direction, and the organizations preferred direction is oriented parallel to this wind (MIV30), and for the third one, the organization direction is perpendicular to the ABL wind direction (ARAT30). This underlines the variety of the organization modes encountered within the ABL.

For the ARAT30 flight, which is a remarkable case according to the anisotropy study results, the airborne data analysis was completed by an analysis of the low frequency parameter fluctuations along the legs, with coherent structures possibly leading to high amplitude perturbations. This kind of approach was applied to the downward visible radiation using a statistical method and revealed an anisotropy of the horizontal size of low-level clouds, with a stretching in favour of the northsouth direction, which confirms the preferred direction pointed out in the previous study. The second method aiming at characterizing the parameters evolution along the legs used a correlation analysis. This study allowed us to confirm the relationships between the vertical velocity, the mixing ratio, the lifting condensation level and the downward visible radiation, that are good tracers of coherent structure occurrence. Moreover, length scales of the order of $2.7 \mathrm{~km}$ (so larger than the turbulence length scales) have been extracted, and confirm the strong probability that organized movements were developed during the ARAT30 flight. Finally, owing to the roughly $90^{\circ}$ difference between the mean ABL wind and the organizational direction, we think that the organizations result from the propagation of gravity waves above the ABL which is supported by the calculation of the Brunt-Väisälä 
wavelength. The various results and observations enabled us to draw a schematic view of the ARAT30 case to highlight the anisotropy in relationship with the skewness, which plays a fundamental rule, as well as a possible interaction between the boundary layer and the low troposphere.

We were able to show from airborne data that it is possible to point out the directional anisotropy character of parameters measured within the ABL, as well as the existence of length scales in the range characteristic of coherent structures. These observations tend to confirm the frequent occurrence of these physical mechanisms in the $\mathrm{ABL}$ with varying configurations relative to the wind direction. The presence of frequent coherent structures in apparently homogeneous convective ABLs should be systematically detected since they require specific parameterizations and infer an anisotropy that prevent fluxes (or other moments) from being correctly estimated by the eddy correlation method. Their contribution to the flux should be estimated with a large-eddy simulation.

\section{Acknowledgements}

We want to thank all the partners of the TRAC98 experiment: the Laboratoire d'Aérologie (LA) technical team and especially the people who helped at the ground and performed numerous soundings with the tethered balloon, and the 'Centre National de Recherches Météorologiques' for running instrumented towers and performing rawinsoundings. We are also very grateful to people from the 'Institut Géographique National', the 'Division Technique de l'Institut National des Sciences de l'Univers' and the 'Centre d'Aviation Météorologique de MétéoFrance' who operated the aircraft and processed the data. We would also like to thank the 'Electricité de France' and 'Degréane' companies who lent two UHF wind profilers. This research was supported by the LA laboratory and Météo-France.

\section{References}

Agee, E. M.: 1984, 'Observations from Space and Thermal Convection: A Historical Perspective', Bull. Amer. Meteorol. Soc. 65, 938-948.

Agee, E. M. and Gilbert, S. R.: 1989, 'An Aircraft Investigation of Mesoscale Convection over Lake Michigan during the 10 January 1984 Cold Air Outbreak', J. Atmos. Sci. 46, 1877-1897.

Atkinson, B. W. and Wu Zang, J.: 1996, 'Mesoscale Shallow Convection in the Atmosphere', Rev. Geophys. 4, 403-431.

Attié, J. L., Durand, P., Druilhet, A., and Saïd, F.: 1997 'Study of Exchange Processes at the Top of the Atmospheric Boundary Layer', in 12th Symposium on Boundary Layers and Turbulence, Vancouver, Canada, July 28-August 1, 1997, pp. 44-45.

Barr, A. G., Betts, A. K., Desjardins, R. L., and MacPherson, J. I.: 1997, 'Comparison of Regional Surface Fluxes from Boundary-Layer Budgets and Aircraft Measurements above Boreal Forest', J. Geophys. Res. 102, 29,213-29,218. 
Brown, E. N., Friehe, C. A., and Lenschow, D. H.: 1983, 'The Use of Pressure Fluctuations on the Nose of an Aircraft for Measuring Air Motion', J. Clim. Appl. Meteorol. 22, 171-180.

Brümmer, B.: 1985, 'Structure, Dynamics, and Energetics of Boundary Layer Rolls from KonTur Aircraft Observations', J. Atmos. Phys. 56, 2613-2636.

Brümmer, B.: 1999, 'Roll and Cell Convection in Wintertime Arctic Cold-Air Outbreaks', J. Atmos. Sci. 5, 237-254.

Caughey, S. J. and Palmer, S. G.: 1979, 'Some Aspects of Turbulence Structure through the Depth of the Convective Boundary Layer', Quart. J. Roy. Meteorol. Soc. 105, 811-827.

Chou, S.-H. and Ferguson, M. P.: 1991, 'Heat Fluxes and Roll Circulations over the Western Gulf Steam during an Intense Cold-Air Outbreak', Boundary-Layer Meteorol. 55, 255-281.

Coulman, C. E.: 1978, 'Boundary Layer Evolution and Nocturnal Dispersal. Part II', Boundary-Layer Meteorol. 14, 493-513.

Deardorff, J. W.: 1974a, 'Three-Dimensional Numerical Study of the Height and Mean Structure of Heated Planetary Boundary Layer', Boundary-Layer Meteorol. 7, 81-106.

Deardorff, J. W.: 1974b, 'Three-Dimensional Numerical Study of Turbulence in an Entraining Mixed Layer', Boundary-Layer Meteorol. 7, 199-226.

Drobinski, P., Brown, R. A., Flamant, P.-H., and Pelon, J.: 1998, 'Evidence of Organized Large Eddies by Ground-Based Doppler Lidar, Sonic Anemometer and Sodar', Boundary-Layer Meteorol. 88, 343-361.

Druilhet, A., Frangi, J. P., GuĆdalia, D., and Fontan, J.: 1983, 'Experimental Studies of the Turbulence Structure Parameters of the Convective Boundary Layer', J. Clim. Appl. Meteorol. 22, 594-608.

Etling, A. and Brown, R. A.: 1993, 'Roll Vortices in the Planetary Boundary Layer', Boundary-Layer Meteorol. 65, 215-248.

Eymard, L. and Weill, A.: 1982, 'Investigation of the Clear Air Convective Structures in the PBL using a Dual Doppler Radar and a Doppler Sodar', J. Appl. Meteorol. 21, 1891-1906.

Garratt, J. R.: 1992, The Atmospheric Boundary Layer, Cambridge Atmospheric and Space Science Series, Cambridge University Press, U.K., 316 pp.

Grant, A. L. M.: 1992, 'The Structure of Turbulence in the Near-Neutral Atmospheric Boundary Layer', J. Atmos. Sci. 49, 226-239.

Greenhut, G. K. and Khalsa, S. J. S.: 1987, 'Convective Elements in the Marine Atmospheric Boundary Layer. Part I: Conditional Sampling', J. Clim. Appl. Meteorol. 26, 813-822.

Guillemet, B., Isaka H., and Mascart P. : 1983, 'Molecular Dissipation of Turbulent Fluctuations in the Convective Mixed Layer', Boundary-Layer Meteorol. 27, 141-162.

Hildebrand, P. H.: 1991, 'Errors in Eddy Correlation Turbulence Measurements from Aircraft: Application to HAPEX-MOBILHY', in T. J. Schmugge and J. C. André (eds.), Land Surface Evaporation: Measurement and Parameterization, Springer-Verlag, New York.

Jacoby-Koaly, S., Campistron, B., Bernard, S., Bénech, B., Girard, F., Dessens, J., Dupont, E., and Carissimo, B.: 2002, 'Estimation of the Turbulent Dissipation Rate from the Doppler Spectral Width Measured in the Atmospheric Boundary-Layer by a UHF Wind Profiler: Comparison with In-Situ Aircraft Data', Boundary-Layer Meteorol., 103, 361-389.

Kaimal, J. C., Wyngaard, J. C., Haugen, D. A., Coté, O. R., Izumi, Y., Caughey, S. J., and Readings, C. J.: 1976, 'Turbulence Structure in the Convective Boundary Layer', J. Atmos. Sci. 33, 21522169.

Kuettner, J. P.: 1971, 'Cloud Bands in the Earth's Atmosphere', Tellus 23, 404-425.

Lambert, D. and Durand, P.: 1999, 'The Marine Atmospheric Boundary Layer during SEMAPHORE. I: Mean Vertical Structure and Non-Axisymmetry of Turbulence', Quart. J. Roy. Meteorol. Soc. 125, 495-512.

Lambert, D., Durand, P., Thoumieux, F., Bénech, B., and Druilhet, A.: 1999, 'The Marine Atmospheric Boundary Layer during SEMAPHORE. II: Turbulence Pprofiles in the Mixed Layer', Quart. J. Roy. Meteorol. Soc. 105, 785-802. 
LeMone, M. A.: 1973, 'The Structure and Dynamics of Horizontal Vortices in the Planetary Boundary Layer', J. Atmos. Sci. 30, 1077-1091.

LeMone, M. A.: 1990, 'Some Observations of Vertical Velocity Skewness in the Convective Planetary Boundary Layer', Amer. Meteorol. Soc. 47, 1163-1169.

LeMone, M. A. and Pennell, W. T.: 1976, 'The Relationship of Trade Wind Cumulus Distribution to Subcloud Layer Fluxes and Structure', Mon. Wea. Rev. 104, 524-539.

Lenschow, D. H.: 1986, 'Aircraft Measurements in the Boundary Layer', in D. H. Lenschow (ed.), Probing the Atmospheric Boundary Layer, Amer. Meteorol. Soc., Boston, pp. 39-56.

Lenschow, D. H. and Stankov: 1986, 'Length Scales in the Convective Boundary Layer', J. Atmos. Sci. 43, 1198-1209.

Lenschow, D. H. and Stephens, P. L.: 1980, 'The Role of Thermals in the Convective Boundary Layer', Boundary-Layer Meteorol. 19, 509-532.

Lenschow, D. H., Wyngaard, J. C., and Pennell, W. T.: 1980, 'Mean-Field and Second-Moment Budgets in a Baroclinic, Convective Boundary Layer', J. Atmos. Sci. 37, 1313-1326.

Lohou, F., Campistron, B., Druilhet, A., Foster, P., and Pages, J.-P.: 1998a, 'Turbulence and Coherent Organizations in the Atmospheric Boundary Layer: A Radar-Aircraft Experimental Approach', Boundary-Layer Meteorol. 86, 147-179.

Lohou, F., Druilhet, A., and Campistron, B.: 1998b, 'Spatial and Temporal Characteristics of Horizontal Rolls and Cells in the Atmospheric Boundary Layer Based on Radar and In-Situ Observations', Boundary-Layer Meteorol. 89, 407-444.

Lohou, F., Druilhet, A., Campistron, B., Rederlsperger, J.-L., and Saïd, F.: 2000, 'Numerical Study of the Impact of Coherent Structures on Vertical Transfers in the Atmospheric Boundary Layer', Boundary-Layer Meteorol. 97, 361-383.

Mahrt, L. and Paumier, J.: 1984, 'Heat Transport in the Atmospheric Boundary Layer', J. Atmos. Sci. 41, 3061-3075.

Mann, J. and Lenschow, D. H.: 1994, 'Errors in Airborne Flux Measurements', J. Geophys. Res. 99, 14519-14526.

Miura, Y.: 1986, 'Aspect Ratios of Longitudinal Rolls and Convection Cells during Cold Air Outbreaks', J. Atmos. Sci. 43, 26-39.

Moeng, C.-H. and Sullivan, P. P.: 1994, 'A Comparison of Shear- and Buoyancy-Driven Planetary Boundary Layer Flows', J. Atmos. Sci. 51, 999-1022.

Moeng, C.-H. and Wyngaard, J. C.: 1984, 'Statistics of Conservative Scalars in the Convective Boundary Layer', J. Atmos. Sci. 41, 3161-3169.

Moeng, C.-H. and Wyngaard, J. C.: 1988, 'Spectral Analysis of Large Eddy Simulation of the Convective Boundary Layer', J. Atmos. Sci. 45, 3575-3587.

Nicholls, S. and LeMone, M.: 1980, 'The Fair Weather Boundary Layer in GATE: The Relationship of Subcloud Fluxes and Structure to the Distribution and Enhancement of Turbulent Clouds', $J$. Atmos. Sci. 37, 2051-2067.

Nicholls, S. and Readings, C. J.: 1979, 'Aircraft Observation of the Structure of the Lower Boundary Layer over the Sea', Quart. J. Roy. Meteorol. Soc. 105, 785-802.

Nieuwstadt, F. T. M. and Duynkerke, P. G. : 1996, 'Turbulence in the Atmospheric Boundary Layer', Atmos. Res. 40, 111-142.

Réchou, A., Durand, P., Druilhet, A., and Bénech, B.: 1995, 'Turbulence Structure of the Boundary Layer Below Marine Clouds in the SOFIA Experiment', Ann. Geophys. 13, 1075-1086.

Reinking, R. F., Doviak, R. J., and Gilmer, R. O.: 1981, 'Clear-Air Roll Vortices and Turbulent Motions as Detected with an Airborne Gust Probe and Dual-Doppler Radar', J. Appl. Meteorol. 20, 678-685.

Scialom, G. and Lemaître, Y.: 1990, 'A New Analysis for Retrieval of the Three-Dimensional Mesoscale Wind Field from Multiple Doppler Radar', J. Atmos. Oceanic Tech. 7, 640-665.

Sorbjan, Z.: 1989, Structure of the Atmospheric Boundary Layer, Prentice Hall, Englewood Cliffs, $\mathrm{NJ}, 317 \mathrm{pp}$ 
Stull, R. B. : 1988, An Introduction to Boundary Layer Meteorology, Kluwer Academic Publishers, Dordrecht, 666 pp.

Verhoef, A.: 1995, Surface Energy Balance of Shrub Vegetation in the Sahel, Ph.D. Dissertation, Wageningen Agricultural University, The Netherlands, 247 pp.

Webb, E. K., Pearman, G. I., and Leuning, R.: 1980, 'Correction of Flux Measurements for Density Effects Due to Heat and Water Vapour Transfer', Quart. J. Roy. Meteorol. Soc. 106, 85-100.

Weckwerth, T. M., Wilson, J. W., and Wakimoto, R. M.: 1996, 'Thermodynamic Variability within the Convective Boundary Layer Due to Horizontal Convective Rolls', Amer. Meteorol. Soc. 124, 769-784.

Willis, G. E. and Deardorff, J. W.: 1974, 'A Laboratory Model of the Unstable Planetary Boundary Layer', J. Atmos. Sci. 31, 1297-1307.

Wyngaard, J. C.: 1983, 'Boundary-Layer Modelling', in F. T. M. Nieuwstadt and H. Van Dop (eds.), Atmospheric Turbulence and Air Pollution Modelling, D. Reidel, Dordrecht, Boston, pp. 69-106.

Wyngaard, J. C. and Izumi, Y. : 1971, 'Local Free Convection, Similarity, and the Budgets of Shear Stress and Heat Flux', J. Atmos. Sci. 28, 1171-1182.

Wyngaard, J. C., Pennel W. T., Lenschow D. H., and LeMone, M.: 1978, 'The Temperature-Humidity Covariance Budget in the Convective Boundary Layer', J. Atmos. Sci. 35, 47-58. 